Supporting Information

\title{
Polymer Self-Assembly Induced Enhancement of Ice Recrystallization Inhibition
}

Panagiotis G. Georgiou, ${ }^{1}$ Huba L. Marton, ${ }^{1}$ Alexander N. Baker, ${ }^{1}$ Thomas R. Congdon, ${ }^{1}$ Thomas F. Whale, ${ }^{1}$ and Matthew I. Gibson ${ }^{1,2 *}$

${ }^{1}$ Department of Chemistry, University of Warwick, Gibbet Hill Road, CV4 7AL, Coventry, UK

${ }^{2}$ Warwick Medical School, University of Warwick, Gibbet Hill Road, CV4 7AL, Coventry, UK

*Corresponding Author: m.i.gibson@,warwick.ac.uk (M.I.G) 


\section{Table of Contents}

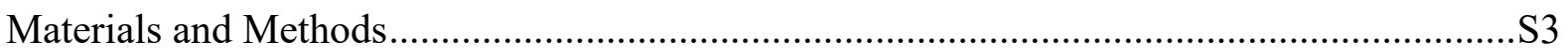

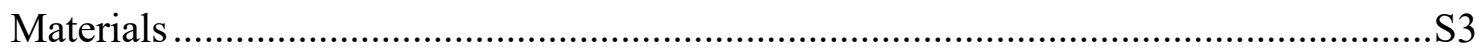

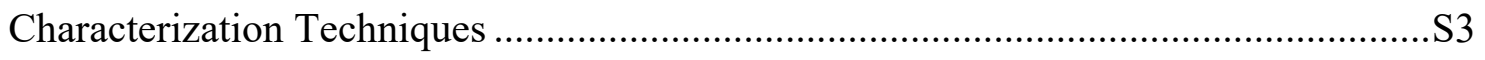

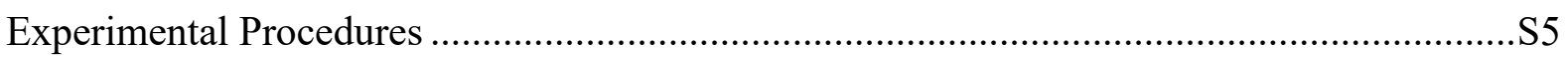

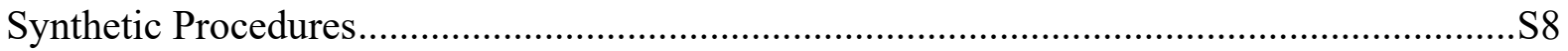

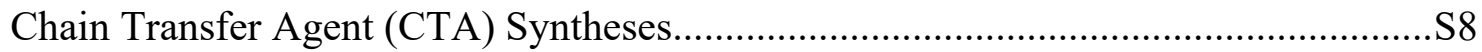

Nanoparticle/Polymer Syntheses................................................................................ 11

Supporting Characterization Data for PEG-based Diblock Copolymer Nanoparticles.........S14

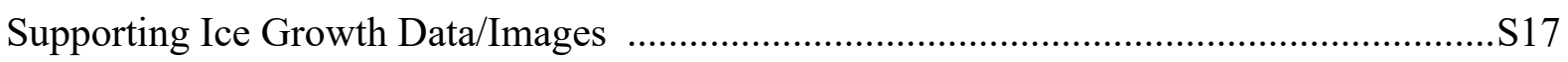

Supporting Characterization Data for PVP-based Diblock Copolymer Nanoparticles. ........S24

Supporting Characterization Data for PDMAC-based Diblock Copolymer Nanoparticles ..S30

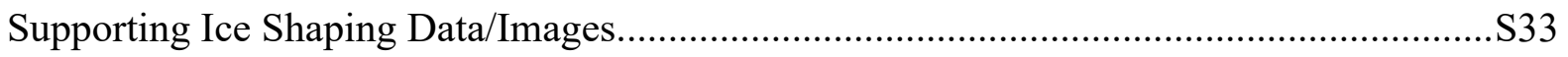

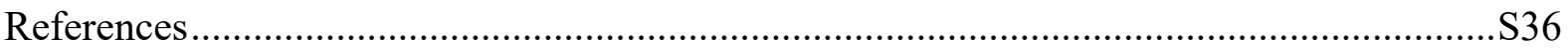




\section{Materials and Methods}

\section{Materials}

All chemicals were used as supplied unless otherwise stated. Poly(ethylene glycol)-based macromolecular chain transfer agents (PEG macro-CTAs), poly(ethylene glycol) methyl ether (4-cyano-4-pentanoate dodecyl trithiocarbonate) (PEG45 mCTA, average $M_{\mathrm{n}}=2,400 \mathrm{~g} \cdot \mathrm{mol}^{-1}$ and $\mathrm{PEG}_{113} \mathrm{mCTA}$, average $\left.M_{\mathrm{n}}=5,400 \mathrm{~g} \cdot \mathrm{mol}^{-1}\right), N$-(isobutoxymethyl)acrylamide $(>98.0 \%$, $i$ BuOMAm), $N$-vinyl-2-pyrrolidinone ( $\geq 99 \%, N V P), 2,2^{\prime}$-azobis(2-methylpropionamidine) dihydrochloride (97\%, VAZO-50), 2,2'-azobis(2-methylpropionitrile) (98\%, AIBN), methyl 2bromopropionate (98\%), carbon disulfide (anhydrous, $\geq 99 \%$ ), 2-bromopropionic acid ( $\geq 99 \%$ ) and sucrose $(\geq 99.5 \%)$ were purchased from Sigma Aldrich. The monomer $N, N$ dimethylacrylamide ( $\geq 99 \%$, DMAC), was also purchased from Sigma Aldrich and passed through a column of basic alumina to remove inhibitor prior to use. Diacetone acrylamide (99\%, DAAm) and potassium ethyl xanthate (>98\%) were obtained from Alfa Aesar. 1Butanethiol ( $\geq 98 \%)$ and sodium chloride ( $\geq 99 \%)$ were purchased from Fisher Scientific. 2,2'azobis[2-(2-imidazolin-2-yl)propane] dihydrochloride, (97\%, VAZO-044) was obtained from Wako Chemicals. Formvar-carbon coated copper grids were purchased from EM Resolutions. Photo-polymerization reaction was conducted using a blue LED strip light (3 meters with 180 LEDs) operating at a wavelength of $\lambda=460-465 \mathrm{~nm}$.

\section{Characterization Techniques}

NMR Spectroscopy. ${ }^{1} \mathrm{H}-\mathrm{NMR}$ and ${ }^{13} \mathrm{C}-\mathrm{NMR}$ spectra were recorded at $300 \mathrm{MHz}$ or $400 \mathrm{MHz}$ on a Bruker DPX-300 or DPX-400 spectrometer respectively, with chloroform- $d\left(\mathrm{CDCl}_{3}\right)$ and methanol- $d_{4}\left(\mathrm{CD}_{3} \mathrm{OD}\right)$ as the solvent. Chemical shifts of protons are reported as $\delta$ in parts per million (ppm) and are relative to tetramethyl silane (TMS) at $\delta=0 \mathrm{ppm}$ when using $\mathrm{CDCl}_{3}$ or solvent residual peak $\left(\mathrm{CH}_{3} \mathrm{OH}, \delta=3.31 \mathrm{ppm}\right)$.

Size Exclusion Chromatography in DMF. Size exclusion chromatography (SEC) analysis was performed on an Agilent Infinity II MDS instrument equipped with differential refractive index (DRI), viscometry (VS), dual angle light scatter (LS) and variable wavelength UV detectors. The system was equipped with 2 x PLgel Mixed D columns $(300 \times 7.5 \mathrm{~mm})$ and a PLgel $5 \mu \mathrm{m}$ guard column. The mobile phase used was DMF (HPLC grade) containing $5 \mathrm{mM} \mathrm{NH}_{4} \mathrm{BF}_{4}$ at $50{ }^{\circ} \mathrm{C}$ at flow rate of $1.0 \mathrm{~mL} \cdot \mathrm{min}^{-1}$. Poly(methyl methacrylate) (PMMA) standards (Agilent EasyVials) were used for calibration between 955,000 - 550 g.mol ${ }^{-1}$. Analyte samples were 
filtered through a nylon membrane with $0.22 \mu \mathrm{m}$ pore size before injection. Number average molecular weights $\left(M_{\mathrm{n}}\right)$, weight average molecular weights $\left(M_{\mathrm{w}}\right)$ and dispersities $\left(\bigoplus_{\mathrm{M}}=\right.$ $\left.M_{\mathrm{w}} / M_{\mathrm{n}}\right)$ were determined by conventional calibration and universal calibration using Agilent GPC/SEC software.

Size Exclusion Chromatography in THF. Size exclusion chromatography (SEC) analysis was performed on an Agilent Infinity II MDS instrument equipped with differential refractive index (DRI), viscometry (VS), dual angle light scatter (LS) and multiple wavelength UV detectors. The system was equipped with 2 x PLgel Mixed C columns $(300 \times 7.5 \mathrm{~mm})$ and a PLgel $5 \mu \mathrm{m}$ guard column. The eluent was THF containing $2 \%$ triethylamine (TEA) and $0.01 \%$ BHT (butylated hydroxytoluene) additives. Samples were run at $1 \mathrm{~mL} \cdot \mathrm{min}^{-1}$ at $30{ }^{\circ} \mathrm{C}$. Polystyrene (PS) standards (Agilent EasyVials) were used for calibration. Analyte samples were filtered through a GVHP membrane with $0.22 \mu \mathrm{m}$ pore size before injection. Number average molecular weights $\left(M_{\mathrm{n}}\right)$, weight average molecular weights $\left(M_{\mathrm{w}}\right)$ and dispersities $\left(\bigoplus_{\mathrm{M}}=\right.$ $\left.M_{\mathrm{w}} / M_{\mathrm{n}}\right)$ were determined by conventional calibration and universal calibration using Agilent GPC/SEC software.

FT-IR Spectroscopy. Fourier Transform-Infrared (FT-IR) spectroscopy measurements were carried out using an Agilent Cary 630 FT-IR spectrometer, in the range of 650 to $4000 \mathrm{~cm}^{-1}$.

Dynamic Light Scattering. Hydrodynamic diameters $\left(D_{\mathrm{h}}\right)$ and size distributions of particles were determined by dynamic light scattering (DLS) using a Malvern Zetasizer Nano ZS with a $4 \mathrm{~mW}$ He-Ne $633 \mathrm{~nm}$ laser module operating at $25^{\circ} \mathrm{C}$. Measurements were carried out at an angle of $173^{\circ}$ (back scattering), and results were analysed using Malvern DTS 7.03 software. All determinations were repeated 5 times with at least 10 measurements recorded for each run. $D_{\mathrm{h}}$ values were calculated using the Stokes-Einstein equation where particles are assumed to be spherical.

Zeta Potential Analysis. Zeta potential was measured by the technique of microelectrophoresis, using a Malvern Zetasizer Nano ZS instrument, at room temperature at $633 \mathrm{~nm}$. All reported measurements were the average of at least five runs. Zeta potential was calculated from the corresponding electrophoretic mobilities $\left(\mu_{\mathrm{E}}\right)$ by using the Henry's correction of the Smoluchowski equation $\left(\mu_{\mathrm{E}}=4 \pi \varepsilon_{0} \varepsilon_{\mathrm{r}} \zeta(1+\kappa \mathrm{r}) / 6 \pi \mu\right)$.

Transmission Electron Microscopy. Dry-state stained TEM imaging was performed on either a JEOL JEM-2100 or a JEOL JEM-2100Plus microscope operating at an acceleration voltage 
of $200 \mathrm{kV}$. All dry-state samples were diluted with MilliQ water and then deposited onto formvar-coated copper grids. After roughly $1 \mathrm{~min}$, excess sample was blotted from the grid and the grid was stained with an aqueous $1 \mathrm{wt} \%$ uranyl acetate (UA) solution for $1 \mathrm{~min}$ prior to blotting, drying and microscopic analysis.

Cryogenic transmission electron microscopy (cryo-TEM) imaging was performed on a JEOL JEM-2100Plus microscope operating at an acceleration voltage of $200 \mathrm{kV}$. Samples for cryoTEM imaging were prepared at $0.5 \% \mathrm{w} / \mathrm{w}$ solids content in MilliQ water by depositing $8 \mu \mathrm{L}$ sample onto plasma-treated lacey-carbon coated grids followed by blotting for approximately $5 \mathrm{~s}$ and plunging into a pool of liquid ethane, cooled using liquid nitrogen, to vitrify the samples. Transfer into a pre-cooled cryo-TEM holder was performed under liquid nitrogen temperatures prior to microscopic analysis.

\section{Experimental Procedures}

Splat Ice Recrystallization Inhibition Assay. Splat cooling assays were performed as previously described by Tomczak et al. ${ }^{1}$ Briefly, a $10 \mu \mathrm{L}$ sample was dropped $1.40 \mathrm{~m}$ onto a chilled glass coverslip, resting on a thin aluminium block cooled to $-78{ }^{\circ} \mathrm{C}$ placed on dry ice. Upon hitting the coverslip, a wafer with diameter of approximately $10 \mathrm{~mm}$ and thickness $10 \mu \mathrm{m}$ was formed instantaneously. The glass coverslip was transferred onto the Linkam cryostage and held at $8^{\circ} \mathrm{C}$ using liquid nitrogen for 30 minutes. Photographs were obtained using an Olympus CX 41 microscope with a UIS-2 20x/0.45/œ0/0-2/FN22 lens and crossed polarisers (Olympus Ltd), equipped with a Canon DSLR 500D digital camera. Images were taken of the initial wafer (to ensure that a polycrystalline sample had been obtained) and again after 30 minutes. Image processing was conducted using ImageJ. In brief, the number of ice crystals in the field of view was measured for each photograph. The average (mean) of these three measurements was then calculated to find the mean grain area (MGS). The average value and error were compared to that of $[\mathrm{NaCl}]=0.05 \mathrm{M}$ solution, as appropriate, as a negative control. Nanoparticle samples solutions were first prepared upon dilution in $[\mathrm{NaCl}]=0.05 \mathrm{M}$ on the range of [PEG, PVP, $\mathrm{PDMAC}]=10-0.5 \mathrm{mg} \cdot \mathrm{mL}^{-1}$.

Sucrose Sandwich Ice Recrystallisation Inhibition Assay. Sucrose sandwich IRI assays were performed as described by Smallwood et $a l^{2,3}$ Briefly, $2 \mu \mathrm{L}$ of PEG $_{45}-b$-PDAAm 100 nanoparticles and $\mathrm{PEG}_{45}$ macro-CTA samples $\left([\mathrm{PEG}]=10 \mathrm{mg} \cdot \mathrm{mL}^{-1}\right)$ containing $45 \mathrm{wt} \%$ sucrose were sandwiched between two circular $14 \mathrm{~mm}$ glass cover slips, and the edges were 
sealed with grease. The coverslips were pressed together in order to produce a liquid film about 10-20 $\mu \mathrm{m}$ thick. Samples were cooled at a rate of $20^{\circ} \mathrm{C} \cdot \mathrm{min}^{-1}$ to a final temperature of $-50{ }^{\circ} \mathrm{C}$ to induce the formation of polycrystalline ice and held at $-50{ }^{\circ} \mathrm{C}$ for 2 min using a Linkam Biological Cryostage BCS196 with T95-Linkpad system controller equipped with a LNP95Liquid nitrogen cooling pump and liquid nitrogen as the coolant (Linkam Scientific Instruments UK). The temperature was then elevated to $-8{ }^{\circ} \mathrm{C}$ at $10{ }^{\circ} \mathrm{C} \cdot \mathrm{min}^{-1}$ and held for 30 minutes. During this time, images were recorded every 10 mins using an Olympus CX41 microscope equipped with a UIS-2 20x/0.45/oo/0-2/FN22 lens (Olympus Ltd.) and a Canon EOS 500D SLR digital.Image processing was conducted using ImageJ.

Modified Sucrose Sandwich Ice Shaping Assay. Briefly, $1 \mathrm{mg} \cdot \mathrm{mL}^{-1}$ of nanoparticle samples were dispersed in $45 \mathrm{wt} \%$ sucrose solution and sandwiched between two glass coverslips and sealed with immersion oil. Samples were cooled to $-50{ }^{\circ} \mathrm{C}$ on a Linkam Biological Cryostage BCS196 with T95-Linkpad system controller equipped with a LNP95-Liquid nitrogen cooling pump, using liquid nitrogen as the coolant (Linkam Scientific Instruments UK). The temperature was then increased to $-8{ }^{\circ} \mathrm{C}$ and held for $1 \mathrm{~h}$ to anneal. The samples were then heated at $0.5{ }^{\circ} \mathrm{C} \cdot \mathrm{min}^{-1}$ until few ice crystals remained and then cooled at $0.05{ }^{\circ} \mathrm{C} \cdot \mathrm{min}^{-1}$ and the shape of ice crystals observed. Micrographs were obtained every $0.1{ }^{\circ} \mathrm{C}$ using an Olympus CX41 microscope equipped with a UIS-2 20x/0.45/oo/0-2/FN22 lens (Olympus Ltd.) and a Canon EOS 500D SLR digital. Image processing was conducted using ImageJ.

Colloidal stability studies during freeze-thaw cycles by DLS. The colloidal stability for $\mathrm{PEG}_{45-}$ $b$-PDAAm 150 and $\mathrm{PVP}_{40}-b$-PDAAm 200 vesicles and their resistance to coagulation upon freezethaw cycles was assessed following typical protocol. ${ }^{4}$ Nanoparticle solutions were diluted in saline solution $([\mathrm{NaCl}]=0.05 \mathrm{M})$ at a final concentration of $10 \% \mathrm{w} / \mathrm{w}$ solids content (to final volume solution of $2 \mathrm{~mL}$ ). Then, nanoparticle solution was submerged in liquid nitrogen for $10 \mathrm{~min}$ and left thaw at room temperature for 1 hour. $100 \mu \mathrm{L}$ of nanoparticle solution was then taken and $D_{\mathrm{h}}$ and PD changes were monitored by DLS. Four freeze-thaw cycles were conducted in total for each nanoparticle formulation.

Ice nucleation measurements. A simple microlitre scale droplet freezing assay was used to establish the ice nucleating effectiveness of the polymer nanoparticles and their precursors. Ice nucleation measurements were performed as previously described by Whale et al. with a slight modification. ${ }^{5}$ While the specific apparatus employed here has not been intercompared with 
other instruments, methods of this type have typically been found to obtain results very compatible with other methods for measuring ice nucleation temperatures. ${ }^{6}$ Where the apparatus described by Whale et al. uses a commercial Stirling engine driven cryocooler to control temperature of freezing droplets the apparatus employed here employs a small $(40 \mathrm{~mm}$ by $40 \mathrm{~mm}$ ) aluminium cold stage thermally bonded to a TEC1-12704 Peltier thermoelectric cooler with Arctic Cooling MX-4 thermal compound. The hot side of the Peltier is cooled using a recirculating chiller. A Meerstetter TEC-1091-PT100 Precision Peltier Controller drives the Peltier, allowing precise control of the temperature of the cold stage. The temperature of the cold stage is independently monitored using two Netshushin PT100 platinum resistance thermometers (NR-141-100S-2-1.0-10-2000PLi-A-3) read by a PicoTech PT-104 Platinum Resistance Data Logger. The PRTs are embedded in the cold stage directly under the area where measurements are conducted. Temperature measurement uncertainty for the PT100s is $\pm 0.15^{\circ} \mathrm{C}$. In practice, the two PT100s typically give the same reading to within $0.05{ }^{\circ} \mathrm{C}$ implying a lower temperature uncertainty however $\pm 0.15{ }^{\circ} \mathrm{C}$ serves as a reasonable conservative estimate.

For the experiments reported here, $1 \mathrm{mg} \cdot \mathrm{ml}^{-1}$ nanoparticle and polymer solutions were made up gravimetrically in MilliQ water. Arrays of 40 to 50 one $\mu 1$ droplets of the nucleant solutions and MilliQ water were pipetted onto a $22 \mathrm{~mm}$ diameter silanized slide (Hampton Research HR3-231) using a Sartorius Picus ${ }^{\circledR}$ electronic micropipette. The slides were placed on the temperature-controlled stage and cooled at a rate of $2^{\circ} \mathrm{C} \min ^{-1}$. A video camera was used to monitor droplet freezing, which was easily observed in ambient light. A custom LabView program was used to directly link temperature measurements to video frames, allowing straightforward determination of freezing temperatures. The first frame in which visible changes leading to freezing were observed was taken as the frame of nucleation. In this way comparative measures of the fraction of droplets frozen as a function of temperature were obtained for the different nucleants. Freezing temperatures of pure water droplets are reported in Figure 6. The 'pure' water freezes several degrees warmer than would be expected for homogeneous ice nucleation, which occurs in the absence of any heterogeneous ice nucleating particles. Purification to the point that homogeneous nucleation occurs is not generally possible and the reported background is typical for the size of droplets used (Polen et al.). ${ }^{7}$ 


\section{Synthetic Procedures}

\section{Chain Transfer Agent (CTA) Syntheses}

\section{Synthesis of 2-(ethoxycarbonothioyl)sulfanyl propanoate (EXEP)}

EXEP chain transfer agent was synthesized according to a previously described method. ${ }^{8}$ Briefly, ethyl acetate $(240 \mathrm{~mL})$ was placed into a round bottom flask equipped with a stirrer bar. Potassium ethyl xanthate $(9.4 \mathrm{~g}, 58.6 \mathrm{mmol}, 1.1 \mathrm{eq})$ was added and then stirred until dissolution. After $30 \mathrm{~min}$, methyl 2-bromopropionate $(5.9 \mathrm{~mL}, 53.3 \mathrm{mmol}, 1 \mathrm{eq})$ was added dropwise and solution left to stir overnight at $60^{\circ} \mathrm{C}$. The solution was then filtered to remove insoluble $\mathrm{KBr}$, washed with cold ethanol and then reduced under vacuum. The resulting residue was re-dissolved in $100 \mathrm{~mL}$ of DCM, washed with water $(2 \times 100 \mathrm{~mL})$, brine $(2 \times 100 \mathrm{~mL})$ and dried over $\mathrm{MgSO}_{4}$. The solution was then filtered and concentrated in vacuo, affording a yellow oil. The crude product was further purified via flash column chromatography using silica gel eluting with hexane:ethyl acetate (9:1) to give the pure product as a yellow oil $(7.63 \mathrm{~g}, 69 \%$ yield). ${ }^{1} \mathrm{H}$ NMR $\left(400 \mathrm{MHz}, \mathrm{CDCl}_{3}\right): \delta(\mathrm{ppm})=4.63\left(\mathrm{q}, 2 \mathrm{H}, \mathrm{CH}_{3} \mathrm{CH}_{2} \mathrm{O}\right), 4.41(\mathrm{q}, 1 \mathrm{H}$, $\left.\mathrm{SCH}\left(\mathrm{CH}_{3}\right) \mathrm{CO}\right), 3.74$ (s, 3H, C(O)OCH $\left.\boldsymbol{H}_{3}\right), 1.57$ (d, 3H, SCH$\left.\left(\mathrm{CH}_{3}\right) \mathrm{CO}\right), 1.42\left(\mathrm{t}, 3 \mathrm{H}, \mathrm{CH}_{3} \mathrm{CH}_{2} \mathrm{O}\right)$. ${ }^{13} \mathrm{C}$ NMR (400 MHz, $\left.\mathrm{CDCl}_{3}\right): \delta(\mathrm{ppm})=212.0,171.9,70.3,52.8,47.0$, 16.9, 13.7. FT-IR (neat): $v\left(\mathrm{~cm}^{-1}\right) 1735(\mathrm{C}=\mathrm{O}), 1213(\mathrm{C}-\mathrm{O}), 1040(\mathrm{C}=\mathrm{S})$. MS (ESI): $\mathrm{m} / \mathrm{z}\left[\mathrm{C}_{7} \mathrm{H}_{12} \mathrm{O}_{3} \mathrm{~S}_{2}+\mathrm{Na}\right]^{+}$calc. $231.1 \mathrm{~g} \mathrm{~mol}^{-1}$, exp. $231.3 \mathrm{~g} \mathrm{~mol}^{-1}$.

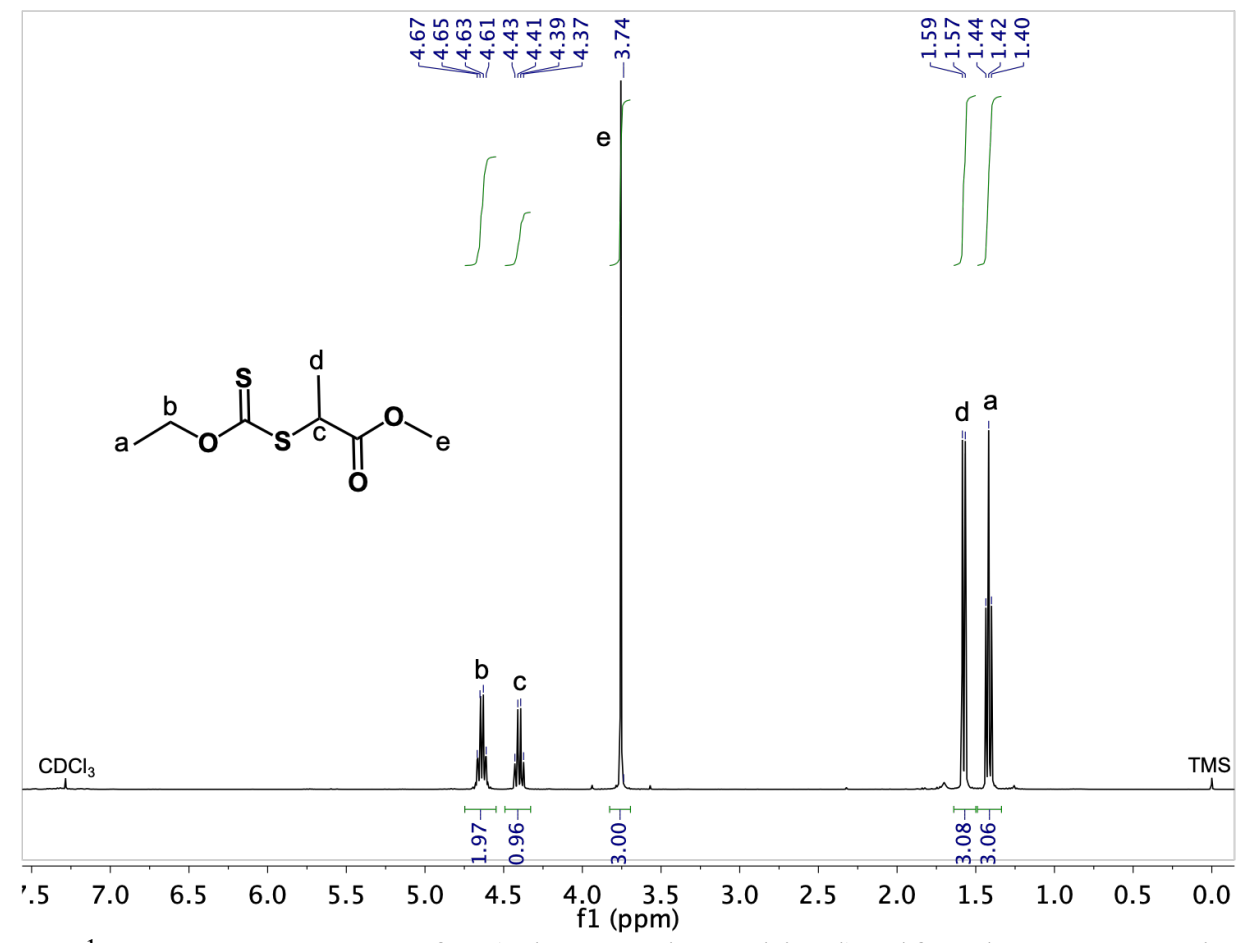

Figure S1. ${ }^{1} \mathrm{H}$ NMR spectrum of 2-(ethoxycarbonothioyl)sulfanyl propanoate in $\mathrm{CDCl}_{3}$. 


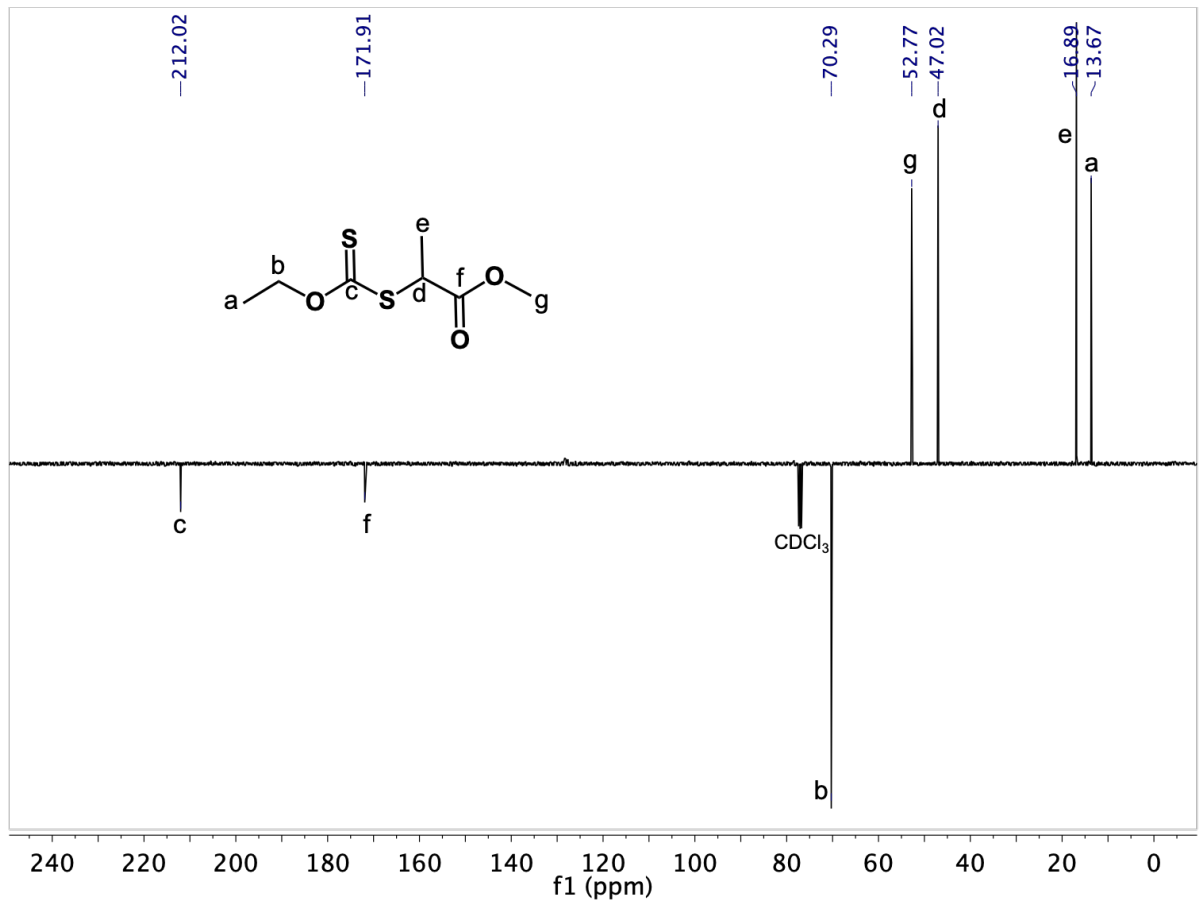

Figure S2. ${ }^{13} \mathrm{C}$ NMR spectrum of 2-(ethoxycarbonothioyl)sulfanyl propanoate in $\mathrm{CDCl}_{3}$.

\section{Synthesis of 2-(((butylthio)carbonothiolyl)thio)propanoic acid}

A previously described process was followed for the synthesis of 2(((butylthio)carbonothiolyl)thio)propanoic acid chain transfer agent. ${ }^{9}$ Briefly, to a stirred mixture of 1-butanethiol $(5.35 \mathrm{~mL}, 50 \mathrm{mmol}, 1 \mathrm{eq})$ and water $(5 \mathrm{~mL}), 50 \% \mathrm{NaOH}$ aqueous solution ( $4.0 \mathrm{~g}$, containing $2.0 \mathrm{~g}, 50 \mathrm{mmol}$ of $\mathrm{NaOH})$ was added. Acetone $(2.5 \mathrm{~mL})$ was then added, and resulting clear, colorless solution was stirred for $30 \mathrm{~min}$, cooled to near-room temperature and treated with carbon disulfide $(3.6 \mathrm{~mL}, 60 \mathrm{mmol}, 1.2 \mathrm{eq})$ to give a clear orange solution. This was stirred for $30 \mathrm{~min}$ then cooled in an ice bath to an internal temperature of $<$ $10^{\circ} \mathrm{C}$. 2-Bromopropanoic acid $(4.65 \mathrm{~mL}, 53 \mathrm{mmol}, 1.1 \mathrm{eq})$ was then added at a slow rate so the temperature did not exceed $30^{\circ} \mathrm{C}$. When the exothermic process had stopped, the ice bath was removed, and water $(7.5 \mathrm{~mL})$ was added. The reaction was stirred at ambient temperature for $24 \mathrm{~h}$ then diluted with water $(12.5 \mathrm{~mL})$ and cooled in an ice bath while $10 \mathrm{M} \mathrm{HCl}(7.5 \mathrm{~mL})$ was added at a rate which kept the temperature $<10^{\circ} \mathrm{C}$. A yellow oil separated and stirring of the mixture was continued at ice temperature until complete solidification of the oil. Solid was collected by suction filtration, pressed and washed with cold water, and dried under reduced pressure to a state of semi-dryness. The lumps were crushed with a spatula; the now-granular solid was resuspended in cold water and stirred for $15 \mathrm{~min}$ then re filtered. The residue was washed with cold water and air-dried to afford a powdery yellow solid, which was recrystallized from hexane to give bright yellow crystals $\left(7.7 \mathrm{~g}, 65 \%\right.$ yield). ${ }^{1} \mathrm{H}$ NMR (400 $\left.\mathrm{MHz}, \mathrm{CDCl}_{3}\right) \delta(\mathrm{ppm})=9.82(\mathrm{br}, 1 \mathrm{H}, \mathrm{COOH}), 4.89\left(\mathrm{q}, 1 \mathrm{H}, \mathrm{OCCHCH}_{3}\right), 3.40(\mathrm{t}, 2 \mathrm{H}$, 
$\left.\mathrm{C}(\mathrm{S}) \mathrm{SCH} \boldsymbol{H}_{2}\right), 1.71\left(\mathrm{~m}, 2 \mathrm{H}, \mathrm{SCH}_{2} \mathrm{CH}_{2}\right), 1.66\left(\mathrm{~d}, 3 \mathrm{H}, \mathrm{C}(\mathrm{O}) \mathrm{CHCH}_{3}\right), 1.46\left(\mathrm{~m}, 2 \mathrm{H}, \mathrm{CH}_{2} \mathrm{CH}_{3}\right), 0.96$ $\left(\mathrm{t}, 3 \mathrm{H}, \mathrm{CH}_{2} \mathrm{CH}_{3}\right) .{ }^{13} \mathrm{C} \mathrm{NMR}\left(400 \mathrm{MHz}, \mathrm{CDCl}_{3}\right) \delta(\mathrm{ppm})=212.8,177.3,47.5,37.1,29.9$,22.1, 16.6, 13.6. MS (ESI): $\mathrm{m} / \mathrm{z}\left[\mathrm{C}_{8} \mathrm{H}_{14} \mathrm{O}_{2} \mathrm{~S}_{3}+\mathrm{Na}\right]^{+}$calc. $261.1 \mathrm{~g} \mathrm{~mol}^{-1}$, exp. $261.3 \mathrm{~g} \mathrm{~mol}^{-1}$.

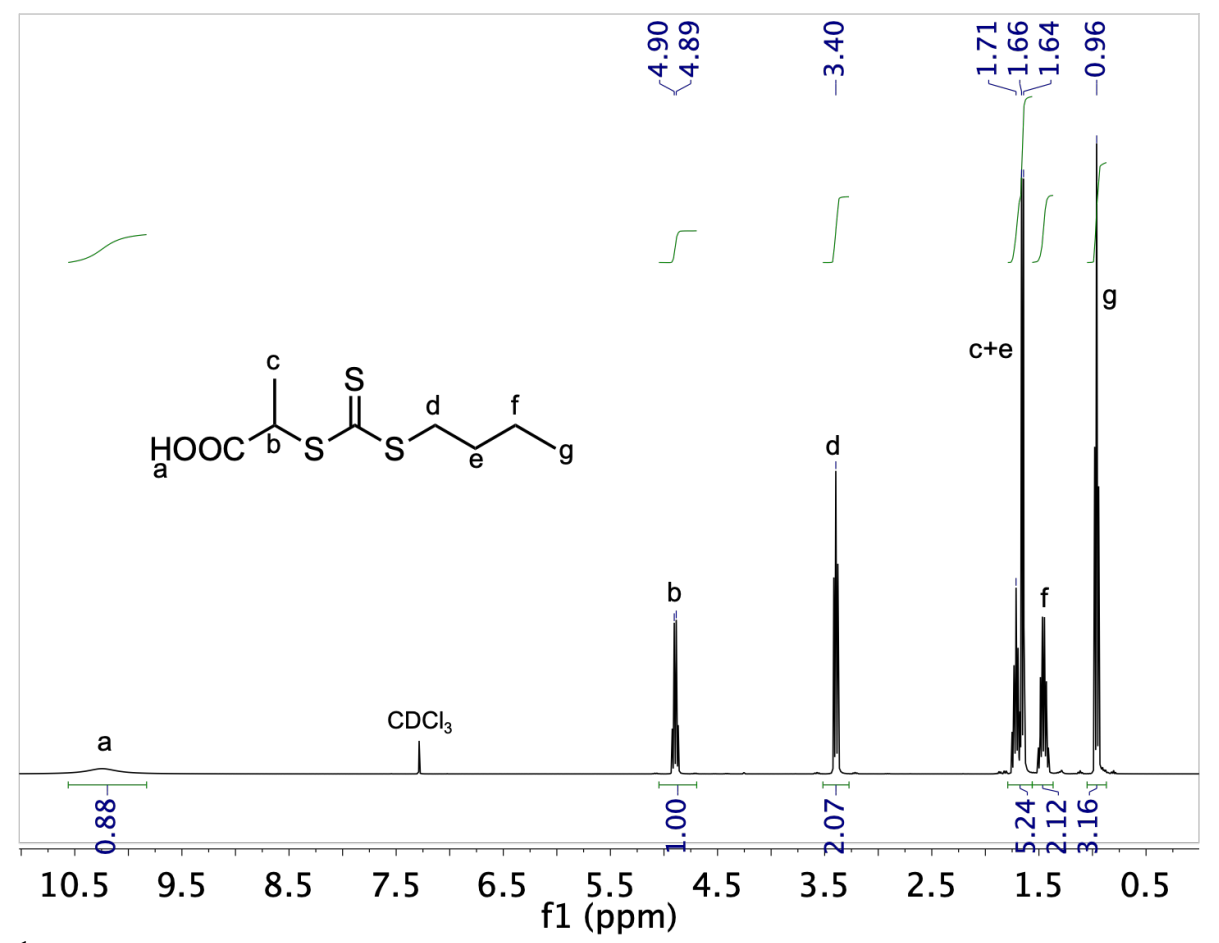

Figure S3. ${ }^{1} \mathrm{H}$ NMR spectrum of 2-(((butylthio)carbonothiolyl)thio)propanoic acid in $\mathrm{CDCl}_{3}$.

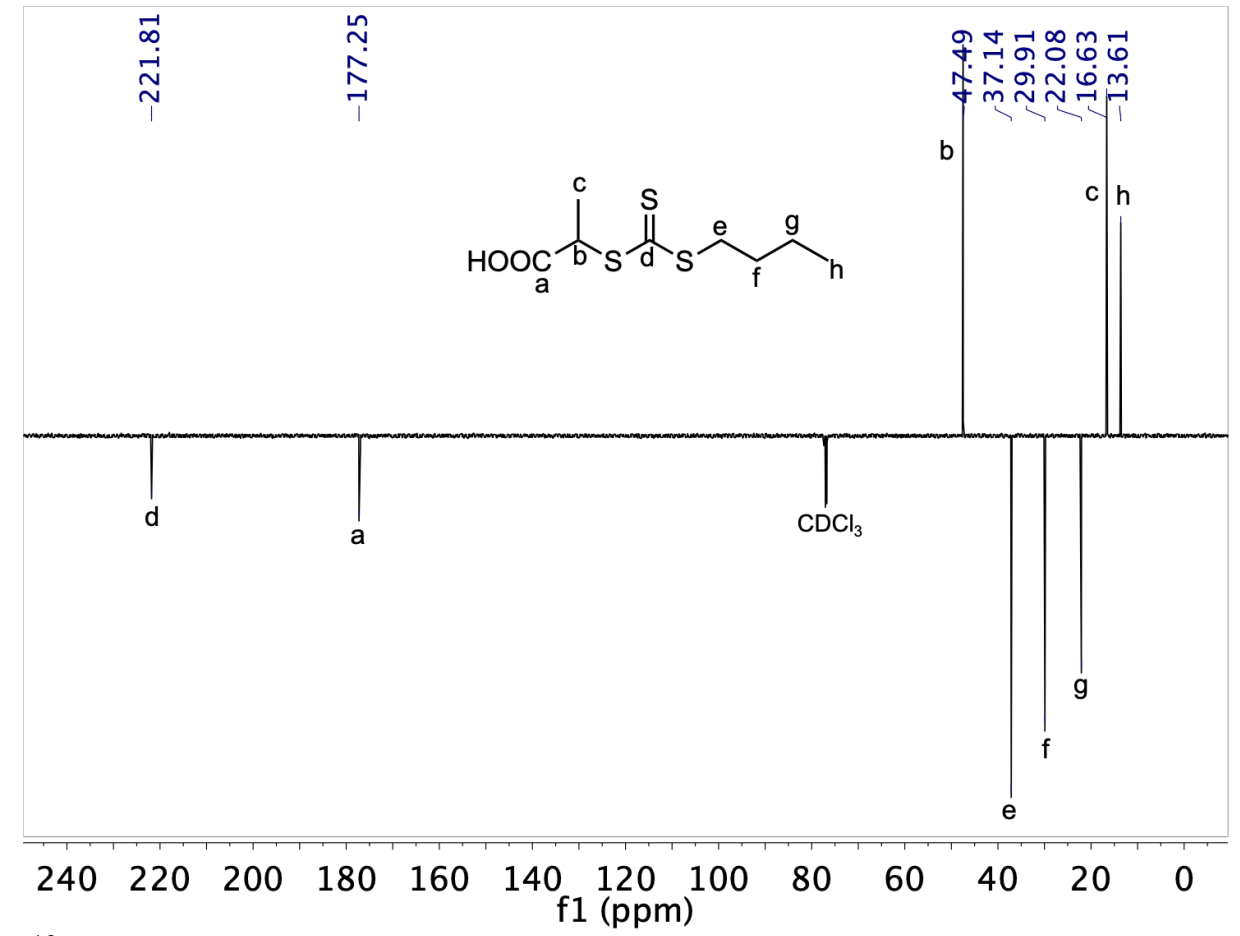

Figure S4. ${ }^{13} \mathrm{C}$ NMR spectrum of 2-(((butylthio)carbonothiolyl)thio)propanoic acid in $\mathrm{CDCl}_{3}$. 


\section{Nanoparticle/Polymer Syntheses}

Synthesis of PEG s5-b-PDAAm $_{n}$ diblock copolymer nanoparticles by aqueous RAFTmediated polymerization-induced self-assembly. A typical synthetic procedure to achieve of $\mathrm{PEG}_{45}-b$-PDAAm 100 diblock copolymer nanoparticles at $10 \% \mathrm{w} / \mathrm{w}$ solids content via aqueous RAFT-mediated PISA is described. To a $6 \mathrm{~mL}$ vial containing a stirring bar, $\mathrm{PEG}_{45}$

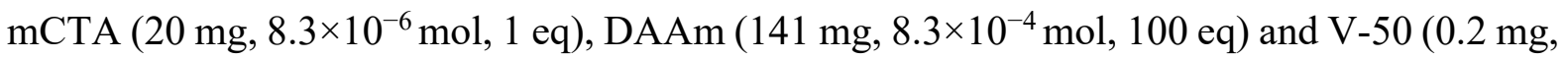
$\left.8.3 \times 10^{-7} \mathrm{~mol}, 0.1 \mathrm{eq}\right)$ were added and dissolved in $\mathrm{NaCl}$ solution $(1.45 \mathrm{~mL},[\mathrm{NaCl}]=0.05 \mathrm{M})$ such that the final concentration of monomer was $10 \mathrm{w} / \mathrm{w} \%$. The vial was sealed with a rubber septum. The resulting polymerization solution was then purged with $\mathrm{N}_{2}(\mathrm{~g})$ for 20 min to remove $\mathrm{O}_{2}(\mathrm{~g})$. The vial was placed into an aluminium heating block which had been pre-heated to $60{ }^{\circ} \mathrm{C}$. After $6 \mathrm{~h}$, the polymerization was quenched by submerging the reaction mixture into liquid $\mathrm{N}_{2}$ and exposing it to air. An aliquot was withdrawn for ${ }^{1} \mathrm{H}-\mathrm{NMR}$ spectroscopic analysis in methanol- $d_{4}$ and SEC analysis in DMF $+5 \mathrm{mM} \mathrm{NH}_{4} \mathrm{BF}_{4}$. The resulting nanoparticle solution was then diluted 10 -fold in $\mathrm{NaCl}$ solution $([\mathrm{NaCl}]=0.05 \mathrm{M})$ and purified by three centrifugation/resuspension cycles at $14000 \mathrm{rpm}$. TEM, DLS, and zeta potential analyses were performed on samples after dilution to an appropriate analysis concentration in MiliQ water. Procedure was repeated for [DAAm]:[PEG 45 mCTA] ratios of 12, 25, 50 and 150. Same procedure was also followed for the synthesis of $\mathrm{PEG}_{45}-b-\mathrm{P}(i \mathrm{BuOMAm})_{100}, \mathrm{PEG}_{113}-b-$ $\mathrm{PDAAm}_{100}$ and $\mathrm{PEG}_{113}-b$-PDAAm 400 diblock copolymer nanoparticles at $10 \% \mathrm{w} / \mathrm{w}$ solids content. Due to insolubility of $\mathrm{PEG}_{45}-b-\mathrm{P}(i \mathrm{BuOMAm})_{100}$ nanoparticle solution on commercial deuterated solvents ${ }^{1} \mathrm{H}$ NMR spectroscopic analysis was not conducted but assumed full monomer consumption based on SEC analysis (Figure S16B). ${ }^{1} \mathrm{H}$ NMR (400 MHz, methanol$\left.d_{4}\right): \delta(\mathrm{ppm})=7.47$ (br s, $\mathrm{NH}$ ), 3.67 (br s, $\mathrm{CH}_{2} \mathrm{CH}_{2} \mathrm{O}$ of PEG), 3.52-2.81 (br m, $\mathrm{CH}_{2}$ of PDAAm backbone and $\mathrm{CH}_{2}$ of PDAAm side chain), 2.20 (br s, $\mathrm{CH}_{3}$ of PDAAm side chain), 2.0 (br s, $\mathrm{CH}$ of PDAAm backbone), 1.41 (br s, $\left(\mathrm{CH}_{3}\right)_{2}$ of PDAAm side chain).

\section{Photo-polymerization of $N$-vinylpyrrolidone using 2-(ethoxycarbonothioyl)sulfanyl}

propanoate. 2-(ethoxycarbonothioyl)sulfanyl propanoate (EXEP) (0.15 g, $0.72 \mathrm{mmol}, 1 \mathrm{eq})$ and $N$-vinylpyrrolidone (NVP) (8 g ( $7.7 \mathrm{~mL}), 72 \mathrm{mmol}, 100 \mathrm{eq})$ were dissolved in $2.04 \mathrm{~mL}$ of dioxane in a vial. Resulting solution was degassed by sparging with $\mathrm{N}_{2}(\mathrm{~g})$ for $15 \mathrm{~min}$ and the sealed vial was incubated at $37^{\circ} \mathrm{C}$ with magnetic stirring under $460 \mathrm{~nm}$ light irradiation for $4 \mathrm{~h}$. After that time, polymerization was quenched by removing sealing and exposing it to air. An aliquot of crude polymerization mixture was withdrawn for ${ }^{1} \mathrm{H}$ NMR in methanol- $d_{4}$ for 
conversion and $M_{\mathrm{n}, \mathrm{NMR}}$ analysis. The reaction was rapidly cooled in liquid nitrogen and precipitated into diethyl ether. The polymer was re-precipitated into diethyl ether from dioxane twice to yield a pale-yellow polymer product that was further dried under vacuum. $M_{\mathrm{n}, \mathrm{NMR}}$ was calculated by end-group analysis by comparing the integrations of the $-\mathrm{CH}_{3}$ signals (t, 1.42 ppm) of methyl end-group with those of the corresponding signals of the $-\mathrm{CH}$ signal (d, 3.69$4.02 \mathrm{ppm})$ of polymer backbone. ${ }^{1} \mathrm{H}$ NMR (400 MHz, methanol- $\left.d_{4}\right): \delta(\mathrm{ppm})=4.02-3.69(\mathrm{br}$ d, $\mathrm{CH}$ of polymer backbone), 3.49-3.13 (br m, $\mathrm{NCH}_{2} \mathrm{CH}_{2}$ of polymer side chain), 2.54-2.17 (br m, $\mathrm{NC}(\mathrm{O}) \mathrm{CH}_{2}$ of polymer side chain), 2.17-1.94 (br s, $\mathrm{NCH}_{2} \mathrm{CH}_{2}$ of polymer side chain), 1.931.45 (br d, $\mathrm{CHCH}_{2}$ of polymer backbone), 1.42 (t, $3 \mathrm{H}, \mathrm{CH}_{3} \mathrm{CH}_{2} \mathrm{O}$ ). $M_{\mathrm{n}, \mathrm{NMR}}=4700 \mathrm{~g} \mathrm{~mol}^{-1}$

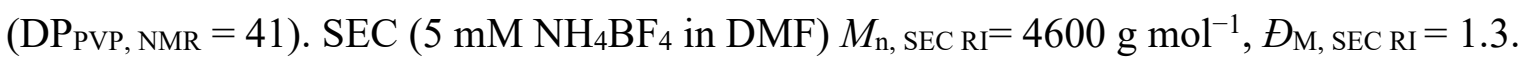

\section{Synthesis of PVP $40-b-\mathrm{P}(\mathrm{DAAm})_{\mathrm{n}}$ diblock copolymer nanoparticles by aqueous RAFT-} mediated polymerization-induced self-assembly. A typical synthetic procedure to achieve of $\mathrm{PVP}_{40}-b$-PDAAm 200 diblock copolymer nanoparticles at $20 \mathrm{wt} \%$ solids content via aqueous RAFT-mediated PISA is described. To a $6 \mathrm{~mL}$ vial containing a stirring bar, $\mathrm{PVP}_{40} \mathrm{mCTA}$

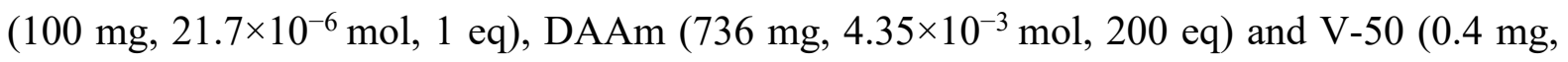
$\left.1.45 \times 10^{-6} \mathrm{~mol}, 0.1 \mathrm{eq}\right)$ were added and dissolved in $\mathrm{NaCl}$ solution $(3.34 \mathrm{~mL},[\mathrm{NaCl}]=0.05 \mathrm{M})$ such that the final concentration of monomer was $20 \mathrm{w} / \mathrm{w} \%$. The vial was sealed with a rubber septum. The resulting polymerization solution was then purged with $\mathrm{N}_{2}(\mathrm{~g})$ for 20 min to remove $\mathrm{O}_{2}(\mathrm{~g})$. The vial was placed into an aluminium heating block which had been pre-heated to $60{ }^{\circ} \mathrm{C}$. After $6 \mathrm{~h}$, the polymerization was quenched by submerging the reaction mixture into liquid $\mathrm{N}_{2}$ and exposing it to air. An aliquot was removed for ${ }^{1} \mathrm{H}-\mathrm{NMR}$ spectroscopic analysis in methanol- $d_{4}$ and SEC analysis in $\mathrm{DMF}+5 \mathrm{mM} \mathrm{NH}_{4} \mathrm{BF}_{4}$. The resulting nanoparticle solution was then diluted 10 -fold in $\mathrm{NaCl}$ solution $([\mathrm{NaCl}]=0.05 \mathrm{M})$ and purified by three centrifugation/resuspension cycles at $14000 \mathrm{rpm}$. TEM, DLS, and zeta potential analyses were performed on samples after dilution to an appropriate analysis concentration. Procedure was repeated for [DAAm]:[PVP $40 \mathrm{mCTA}]$ ratios of 25, 50 and 100. ${ }^{1} \mathrm{H}$ NMR (400 MHz, methanol$\left.d_{4}\right): \delta(\mathrm{ppm})=7.47$ (br s, $\mathrm{NH}$ ), 3.67 (br s, $\mathrm{CH}_{2} \mathrm{CH}_{2} \mathrm{O}$ of PEG), 3.52-2.81 (br m, $\mathrm{CH}_{2}$ of PDAAm backbone and $\mathrm{CH}_{2}$ of PDAAm side chain), 2.20 (br s, $\mathrm{CH}_{3}$ of PDAAm side chain), 2.0 (br s, $\mathrm{CH}$ of PDAAm backbone), 1.41 (br s, $\left(\mathrm{CH}_{3}\right)_{2}$ of PDAAm side chain).

\section{Polymerization of $\quad \mathrm{N}, \mathrm{N}$-dimethylacrylamide $\quad$ (DMAC) using 2-} (((butylthio)carbonothiolyl)thio) propanoic acid. A vial was charged with 2(((butylthio)carbonothiolyl)thio) propanoic acid (100 mg, $0.42 \mathrm{mmol}, 1 \mathrm{eq})$, DMAC (1.66 g, 
$16.8 \mathrm{mmol}, 40 \mathrm{eq}), \operatorname{AIBN}(6.9 \mathrm{mg}, 0.04 \mathrm{mmol}, 0.1 \mathrm{eq})$, and $7 \mathrm{~mL}$ of dioxane. The vial was then sealed and deoxygenated using three successive cycles of freeze-pump-thaw to remove $\mathrm{O}_{2}(\mathrm{~g})$. The vial was placed into an aluminium heating block which had been pre-heated to $70{ }^{\circ} \mathrm{C}$ to initiate polymerization. After $2 \mathrm{~h}$, the polymerization was quenched by exposing the vial to air and submerging it into liquid $\mathrm{N}_{2}$. An aliquot was withdrawn for determination of monomer conversion by ${ }^{1} \mathrm{H}$ NMR spectroscopy. The polymer was precipitated into diethyl ether from dioxane twice to yield a yellow polymer product that was further dried under vacuum. $M_{\mathrm{n}, \mathrm{NMR}}$ was calculated by end-group analysis by comparing the integrations of the $-\mathrm{CH}_{3}$ signals $(\mathrm{t}$, $0.97 \mathrm{ppm}$ ) of methyl end-group with those of the corresponding signals of the $-\mathrm{CH}$ signal (br m, 2.83-2.40 ppm) of polymer backbone. ${ }^{1} \mathrm{H}$ NMR (400 MHz, methanol- $\left.d_{4}\right): \delta(\mathrm{ppm})=3.45$ (t, 2H, C(S)SCH$H_{2}$ ), 3.24-2.85 (br m, N(CH $)_{2}$ of polymer side chain), 2.83-2.40 (br m, $\mathrm{CH}_{2} \mathrm{CH}$ of polymer backbone), 1.94-1.22 (br m, $\mathrm{CHCH}_{2}$ of polymer backbone). $M_{\mathrm{n}, \mathrm{NMR}}=4200 \mathrm{~g} \mathrm{~mol}^{-1}$ $\left(\mathrm{DP}_{\mathrm{PDMAC}}\right.$ NMR $\left.=40\right)$. SEC $\left(5 \mathrm{mM} \mathrm{NH}_{4} \mathrm{BF}_{4}\right.$ in DMF $) M_{\mathrm{n}, \mathrm{SEC} \mathrm{RI}}=4800 \mathrm{~g} \mathrm{~mol}^{-1}, \bigoplus_{\mathrm{M}, \mathrm{SEC} \mathrm{RI}}=1.1$.

\section{Synthesis of PDMAC $40-b-P(D A A m)_{200}$ diblock copolymer nanoparticles by aqueous} RAFT-mediated polymerization-induced self-assembly. Similar with previous PISA protocols, to a $6 \mathrm{~mL}$ vial containing a stirring bar, PDMAc $40 \mathrm{mCTA}\left(80 \mathrm{mg}, 1.90 \times 10^{-5} \mathrm{~mol}, 1\right.$ eq), DAAm (645 mg, 3.81 $\left.\times 10^{-3} \mathrm{~mol}, 200 \mathrm{eq}\right)$ and V-50 (0.5 mg, 1.9 $\left.\times 10^{-6} \mathrm{~mol}, 0.1 \mathrm{eq}\right)$ were added and dissolved in $\mathrm{NaCl}$ solution $(2.9 \mathrm{~mL},[\mathrm{NaCl}]=0.05 \mathrm{M})$ such that the final concentration of monomer was $20 \mathrm{w} / \mathrm{w} \%$. The vial was sealed with a rubber septum. The resulting polymerization solution was then purged with $\mathrm{N}_{2}(\mathrm{~g})$ for 20 min to remove $\mathrm{O}_{2}(\mathrm{~g})$. The vial was placed into an aluminium heating block which had been pre-heated to $60^{\circ} \mathrm{C}$. After 6 $h$, the polymerization was quenched by submerging the reaction mixture into liquid $\mathrm{N}_{2}$ and exposing it to air. An aliquot was removed for ${ }^{1} \mathrm{H}-\mathrm{NMR}$ spectroscopic analysis in methanol- $d_{4}$ and SEC analysis in DMF $+5 \mathrm{mM} \mathrm{NH}_{4} \mathrm{BF}_{4}$. The resulting nanoparticle solution was then diluted 10-fold in $\mathrm{NaCl}$ solution $([\mathrm{NaCl}]=0.05 \mathrm{M})$ and purified by three centrifugation/resuspension cycles at $14000 \mathrm{rpm}$. TEM, DLS, and zeta potential analyses were performed on samples after dilution to an appropriate analysis concentration. ${ }^{1} \mathrm{H}$ NMR (400 $\mathrm{MHz}$, methanol- $\left.d_{4}\right): \delta(\mathrm{ppm})=7.49$ (br s, $\mathrm{NH}$ ), 3.67 (br s, $\mathrm{CH}_{2} \mathrm{CH}_{2} \mathrm{O}$ of PEG), 3.52-2.81 (br m, $\mathrm{CH}_{2}$ of PDAAm backbone and $\mathrm{CH}_{2}$ of PDAAm side chain), 2.20 (br s, $\mathrm{CH}_{3}$ of PDAAm side chain), 2.0 (br s, $\mathrm{CH}$ of PDAAm backbone), 1.41 (br s, $\left(\mathrm{CH}_{3}\right)_{2}$ of PDAAm side chain). $M_{\mathrm{n}, \mathrm{NMR}}=38,000 \mathrm{~g} \mathrm{~mol}^{-1}$. SEC $\left(5 \mathrm{mM} \mathrm{NH}_{4} \mathrm{BF}_{4}\right.$ in DMF $) M_{\mathrm{n}, \mathrm{SEC} \mathrm{RI}}=32,000 \mathrm{~g} \mathrm{~mol}^{-1}, \bigoplus_{\mathrm{M}}, \mathrm{SEC} \mathrm{RI}$ $=1.5$. 
Supporting Characterization Data for PEG-Based Diblock Copolymer Nanoparticles

Table S1. Molecular characteristics of $\mathrm{PEG}_{45}-b-\mathrm{PDAAm}_{\mathrm{n}}$ diblock copolymers prepared via aqueous RAFT-PISA using different initial [DAAm]/[PEG $45 \mathrm{mCTA}]$ ratios, as determined by ${ }^{1} \mathrm{H}-\mathrm{NMR}$ spectroscopy and SEC analysis.

\begin{tabular}{|c|c|c|c|c|}
\hline [DAAm]/[PEG 45 mCTA] & $\%$ Conv. $^{a}$ & $M_{\mathrm{n}, \text { theo }}(\mathrm{kDa})^{b}$ & $M_{\mathbf{n}, \operatorname{SEC}}(\mathbf{k D a})^{c}$ & $\boldsymbol{D}_{\mathrm{M}, \mathrm{SEC}^{c}}$ \\
\hline 0 & ----- & 2.4 & 4.1 & 1.1 \\
\hline 12 & 95 & 4.4 & 6.1 & 1.2 \\
\hline 25 & $>99$ & 6.6 & 8.4 & 1.3 \\
\hline 50 & $>99$ & 10.9 & 14.6 & 1.5 \\
\hline 100 & $>99$ & 19.3 & 23.9 & 1.6 \\
\hline 150 & 97 & 27.7 & 25.8 & 2.4 \\
\hline
\end{tabular}

${ }^{a}$ Monomer conversion calculated from ${ }^{1} \mathrm{H}-\mathrm{NMR}$ spectroscopy in methanol- $d_{4} \cdot{ }^{b}$ Calculated from conversion. ${ }^{c} M_{\mathrm{n}}$ and $\emptyset_{\mathrm{M}}$ values calculated from PMMA standards using DMF $+5 \mathrm{mM} \mathrm{NH}_{4} \mathrm{BF}_{4}$ as the eluent.

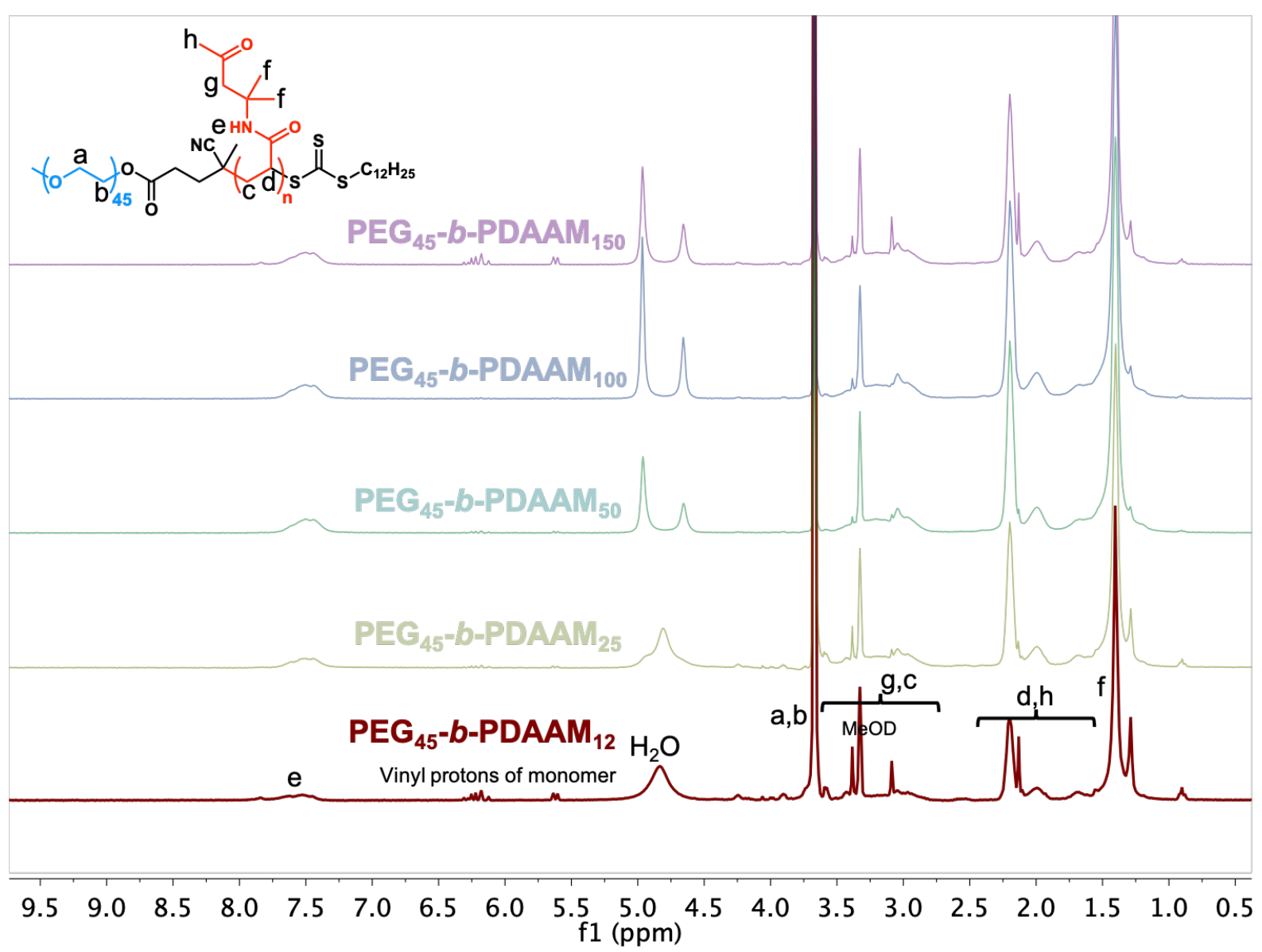

Figure S5. Stacked ${ }^{1} \mathrm{H}-\mathrm{NMR}$ spectra of $\mathrm{PEG}_{45}-b-\mathrm{PDAAm}_{\mathrm{n}}(\mathrm{n}=12,25,50,100,150)$ diblock copolymers recorded in methanol- $d_{4}$, showing quantitative monomer consumption ( $\left.>95 \%\right)$. 


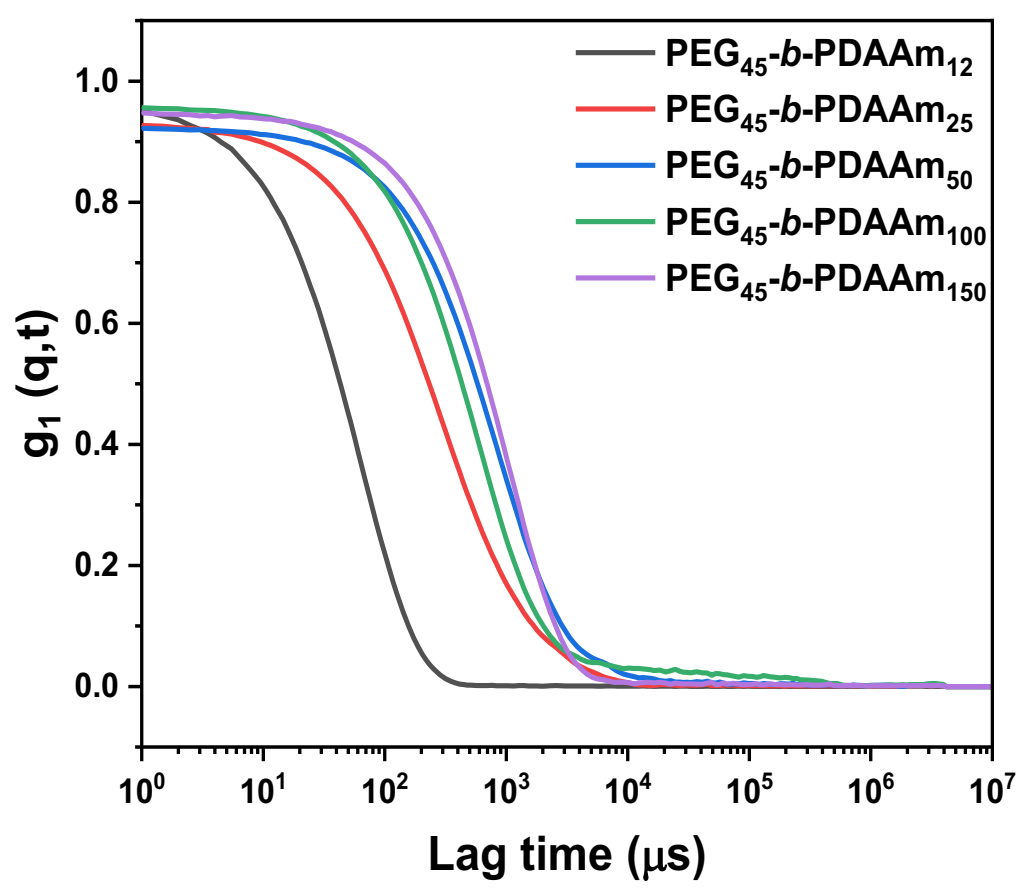

Figure S6. Stacked autocorrelation functions of $\mathrm{PEG}_{45}-b-\mathrm{PDAAm}_{\mathrm{n}}(\mathrm{n}=12,25,50,100,150)$ diblock copolymer nanoparticles developed by aqueous RAFT-mediated PISA.

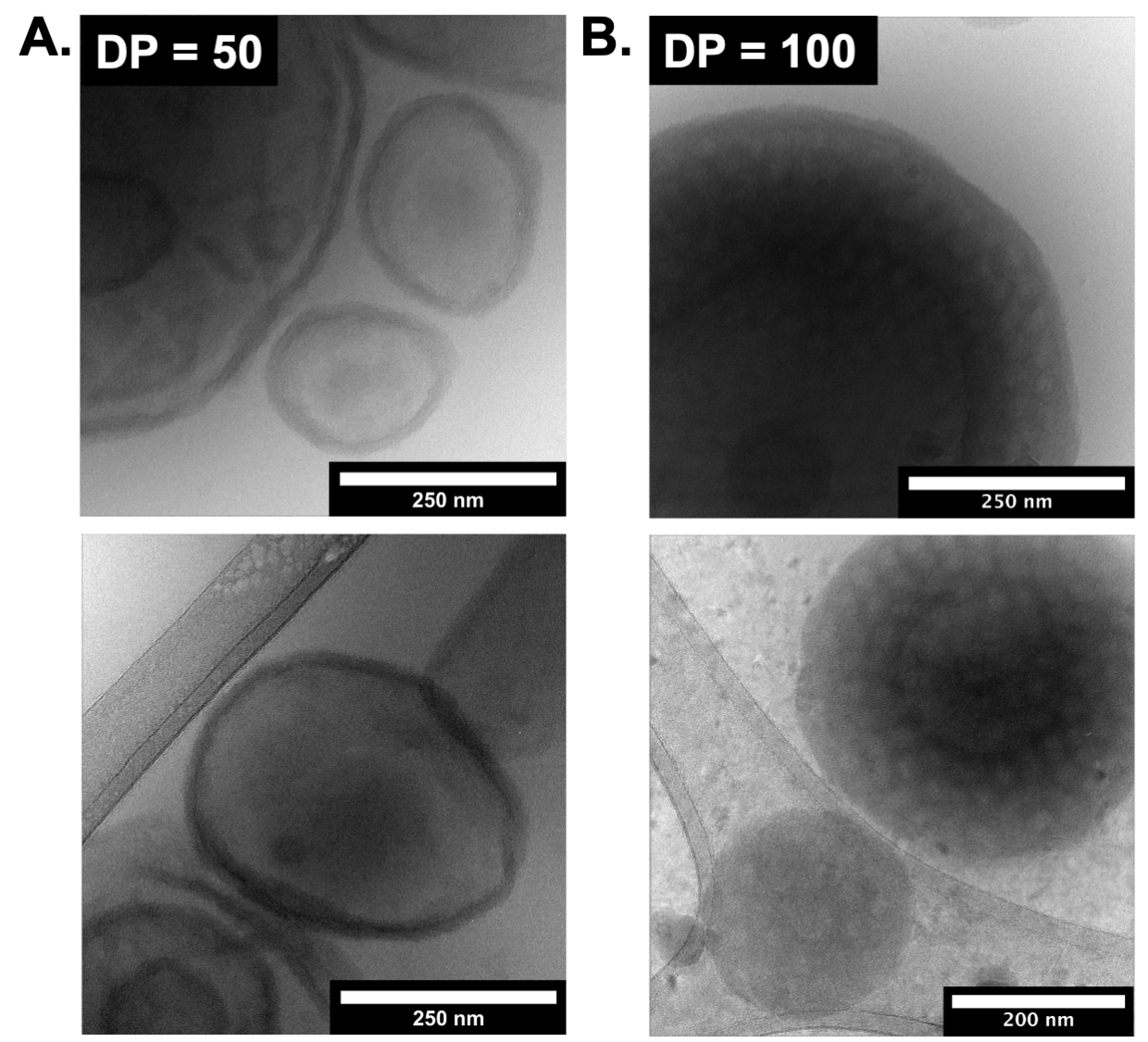

Figure S7. Representative cryogenic TEM images (cryo-TEM) for (A) $\mathrm{PEG}_{45}-b$-PDAAm 50 and (B) PEG $_{45}-b$-PDAAm 100 indicating the formation of bilayer lamella and vesicles and perforated vesicles respectively. 
A. $\mathrm{PEG}_{45}$ macro-CTA

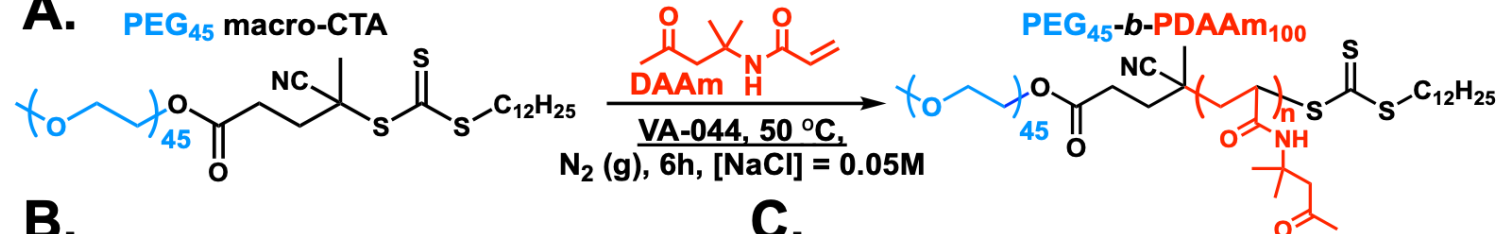

B.

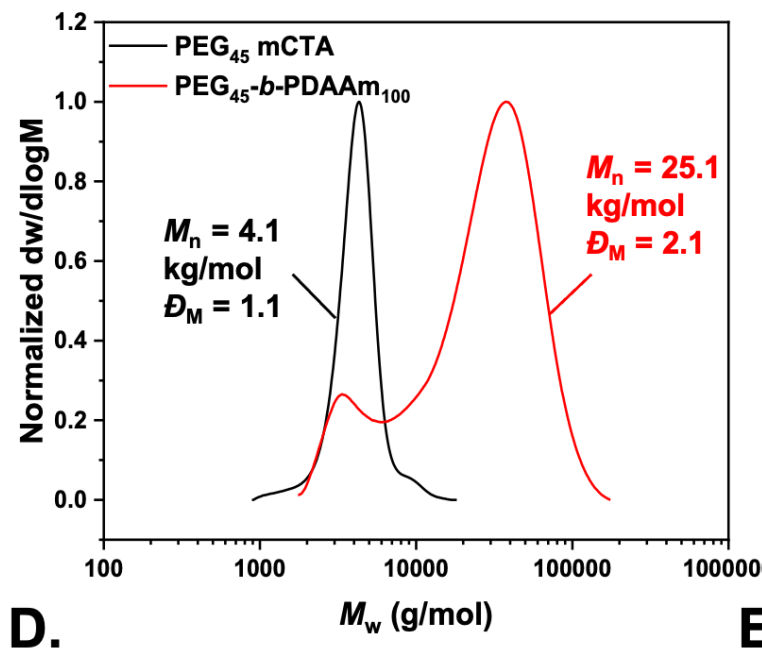

C.

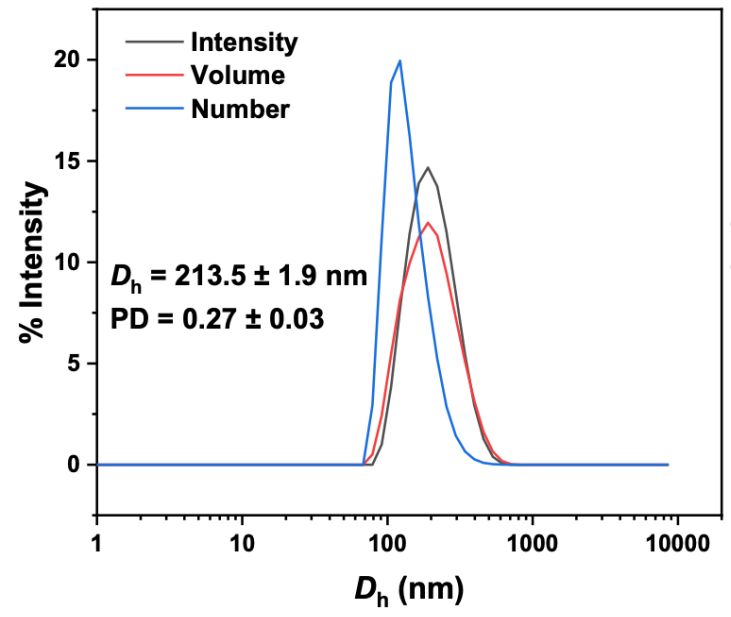

E.

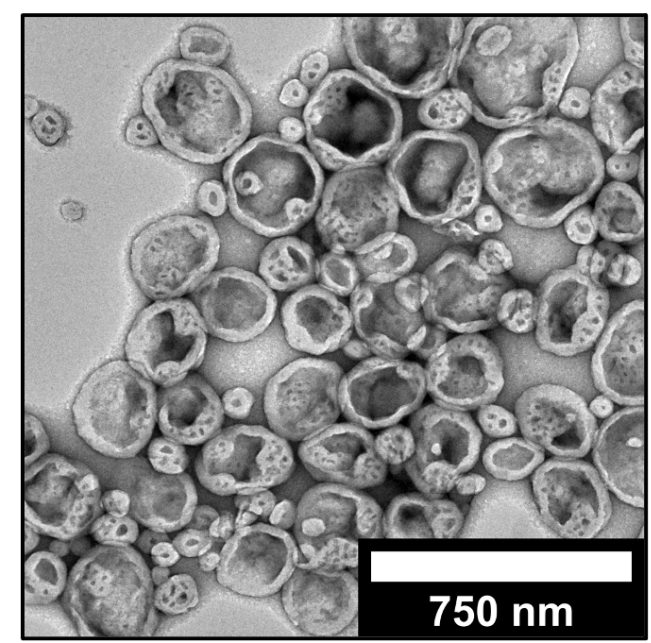

Figure S8. (A) Characterization of $\mathrm{PEG}_{45}-b$-PDAAm 100 diblock copolymer nanoparticles via aqueous RAFT-mediated PISA in the presence of $[\mathrm{NaCl}]=0.05 \mathrm{M}$. Polymerization was conducted at $50{ }^{\circ} \mathrm{C}$ and initiated using 2,2'-azobis[2-(2-imidazolin-2-yl)propane] dihydrochloride (VA-044). (B) Normalized SEC RI molecular weight distributions for PEG $_{45}$ mCTA (black trace) and $\mathrm{PEG}_{45}-b$-PDAAm 100 (red trace) diblock copolymer nanoparticles. $M_{\mathrm{n}}$ and $\emptyset_{\mathrm{M}}$ values calculated from PMMA standards using DMF $+5 \mathrm{mM} \mathrm{NH}_{4} \mathrm{BF}_{4}$ as the eluent. (C) Representative dry-state TEM image, stained with $1 \mathrm{wt} \%$ UA solution. (D) Intensityweighted size distribution along with average $D_{\mathrm{h}}$ and PD values (the error shows the standard deviation from 5 repeat measurements), and (E) autocorrelation function obtained by DLS. 


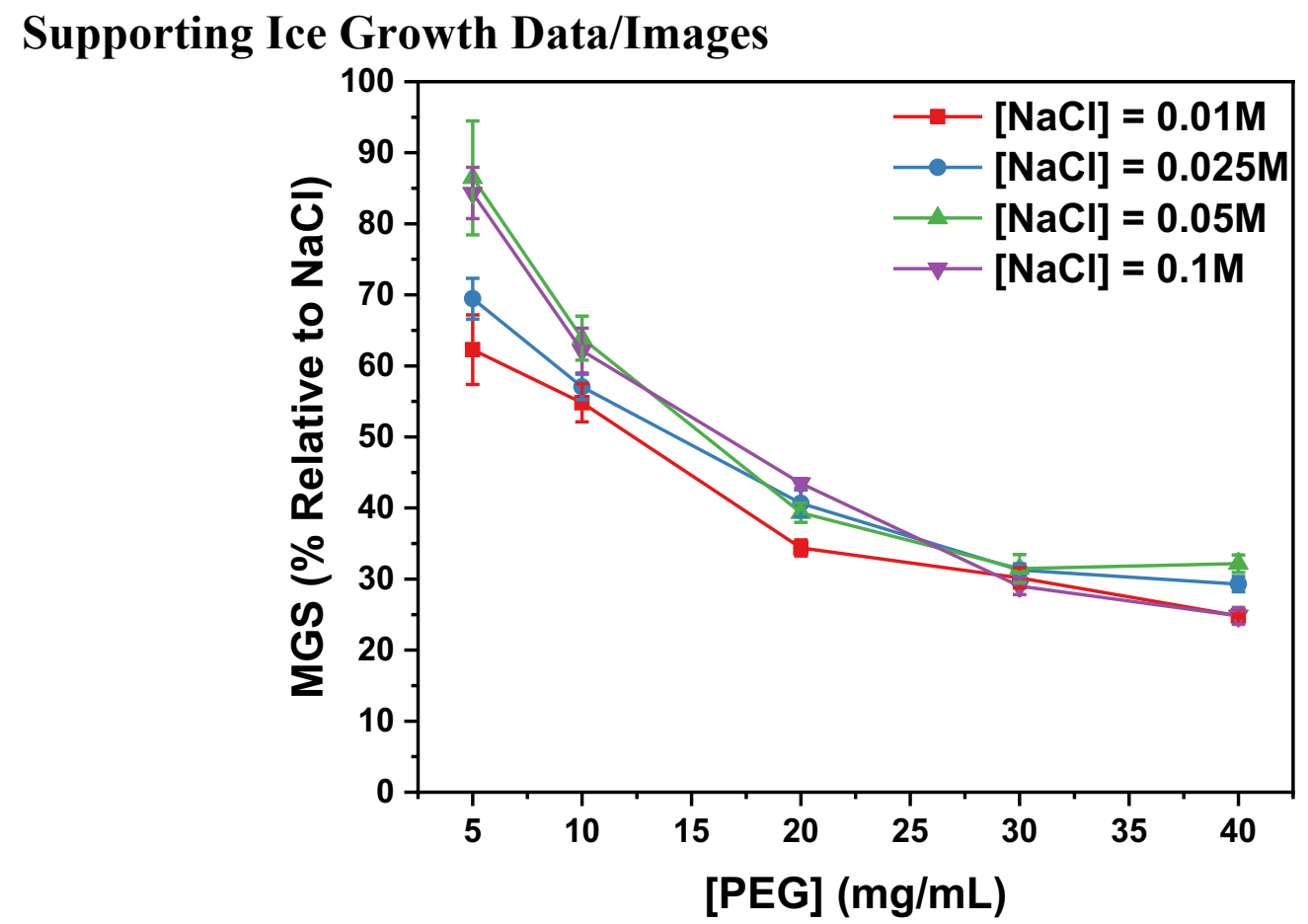

Figure S9. Ice recrystallization inhibition activity summary for $\mathrm{PEG}_{113}$ macro-CTA $\left(M_{\mathrm{n}}=\right.$ $5,400)$ in $0.01,0.025,0.05$ and $0.1 \mathrm{M} \mathrm{NaCl}$ solutions corrected to [PEG]. Error bars are $\pm \mathrm{SD}$ from a minimum of three repeats. The percent mean grain size (MGS) was reported relative to saline controls in $[\mathrm{NaCl}]=0.01,0.025,0.05$ and $0.1 \mathrm{M}$.

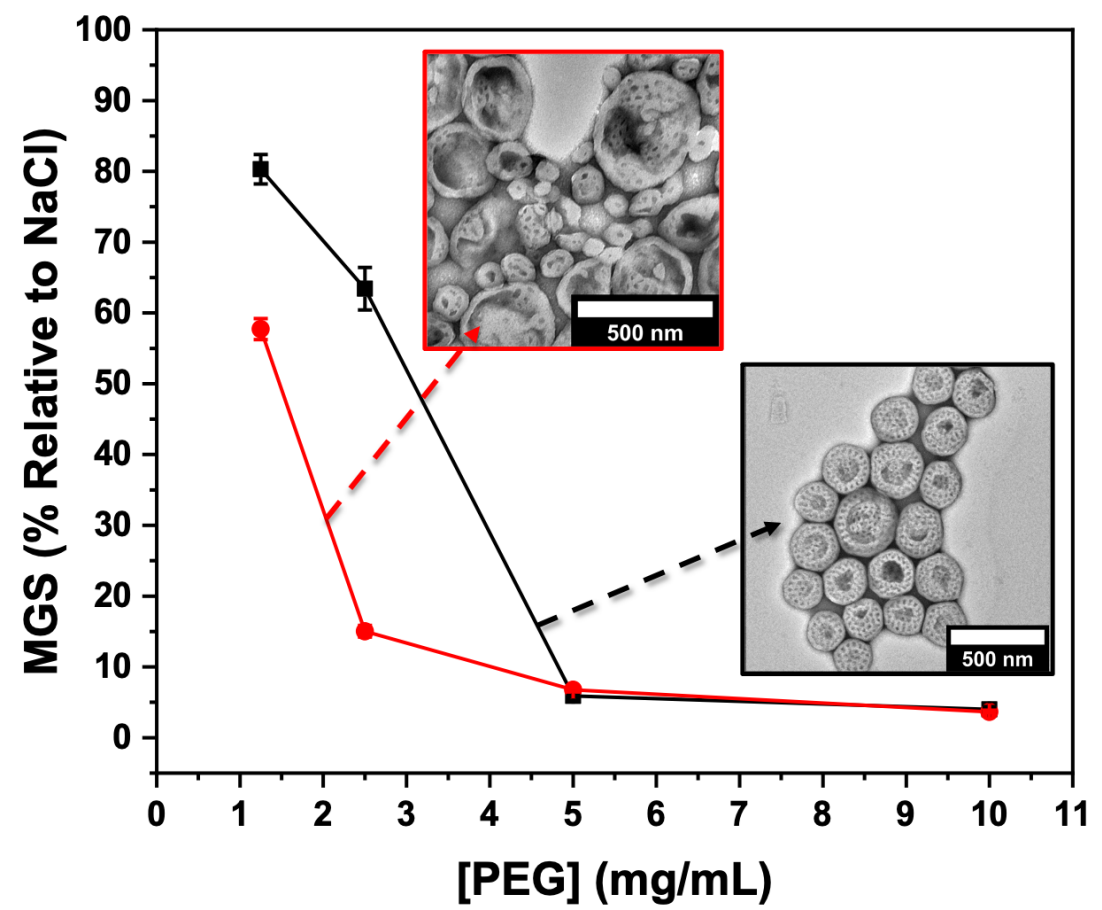

Figure S10. Ice recrystallization inhibition activity summary for $\mathrm{PEG}_{45}-b-\mathrm{PDAAm}_{100}$ diblock copolymer perforated vesicles (corrected to [PEG]), developed via aqueous RAFT-mediated PISA in the presence of $[\mathrm{NaCl}]=0.05 \mathrm{M}$. Polymerizations were initiated using either VA-044 (red trend) or V-50 (black trend) at 50 or $60^{\circ} \mathrm{C}$ respectively. Insets: representative TEM photos for $\mathrm{PEG}_{45}-b$-PDAAm 100 samples. Error bars are \pm SD from a minimum of three repeats. The percent mean grain size (MGS) was reported relative to saline controls in $[\mathrm{NaCl}]=0.05 \mathrm{M}$. 

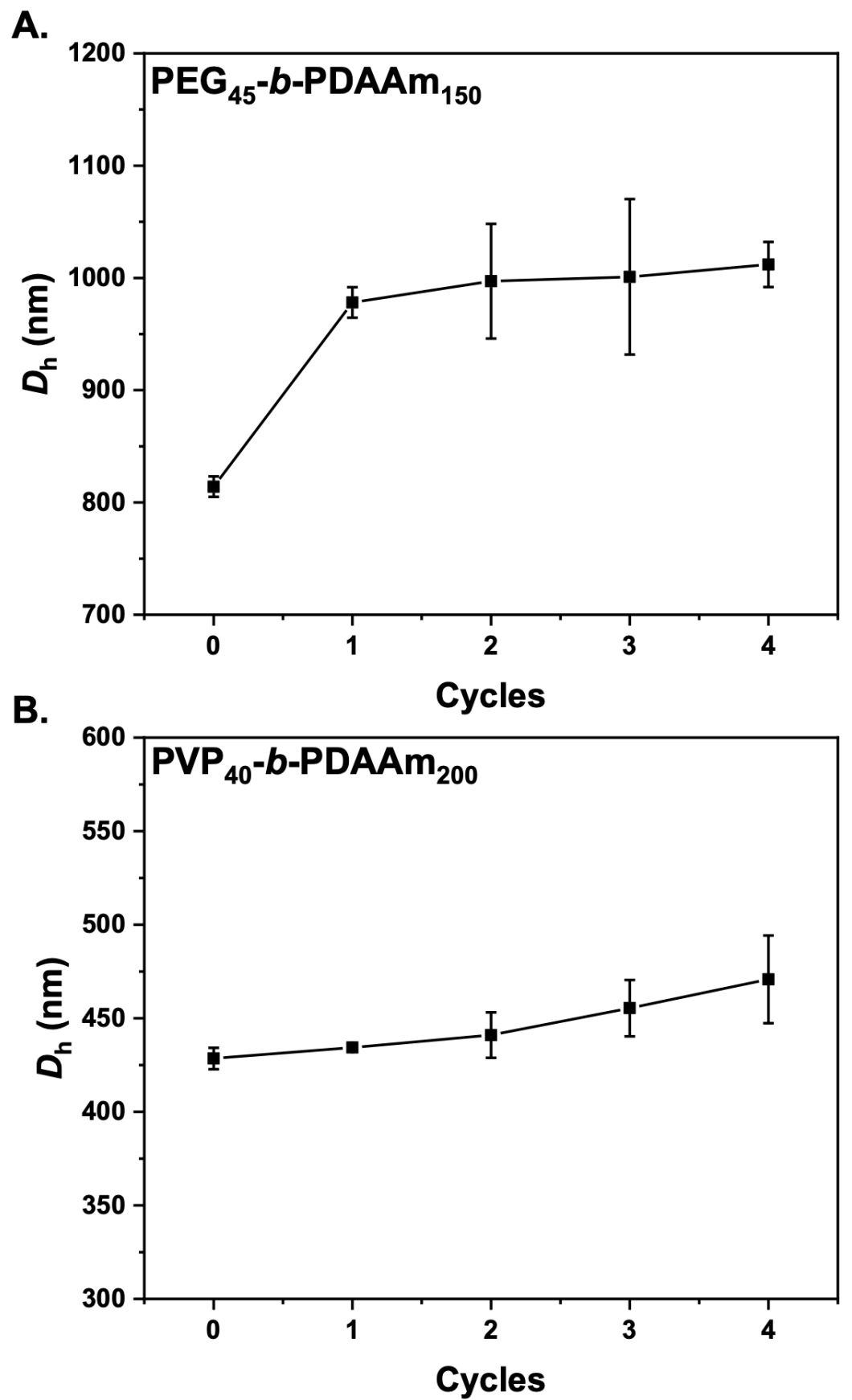

Figure S11. Colloidal stability studies by monitoring hydrodynamic diameter $\left(D_{\mathrm{h}}\right)$ by DLS for (A) $\mathrm{PEG}_{45}-b$-PDAAm 150 and (B) $\mathrm{PVP}_{40}-b$-PDAAm 200 vesicles in saline medium $([\mathrm{NaCl}]=$ $0.05 \mathrm{M}$ ) upon four freeze-thaw cycles (the error bars show the standard deviation from 5 repeat measurements). 


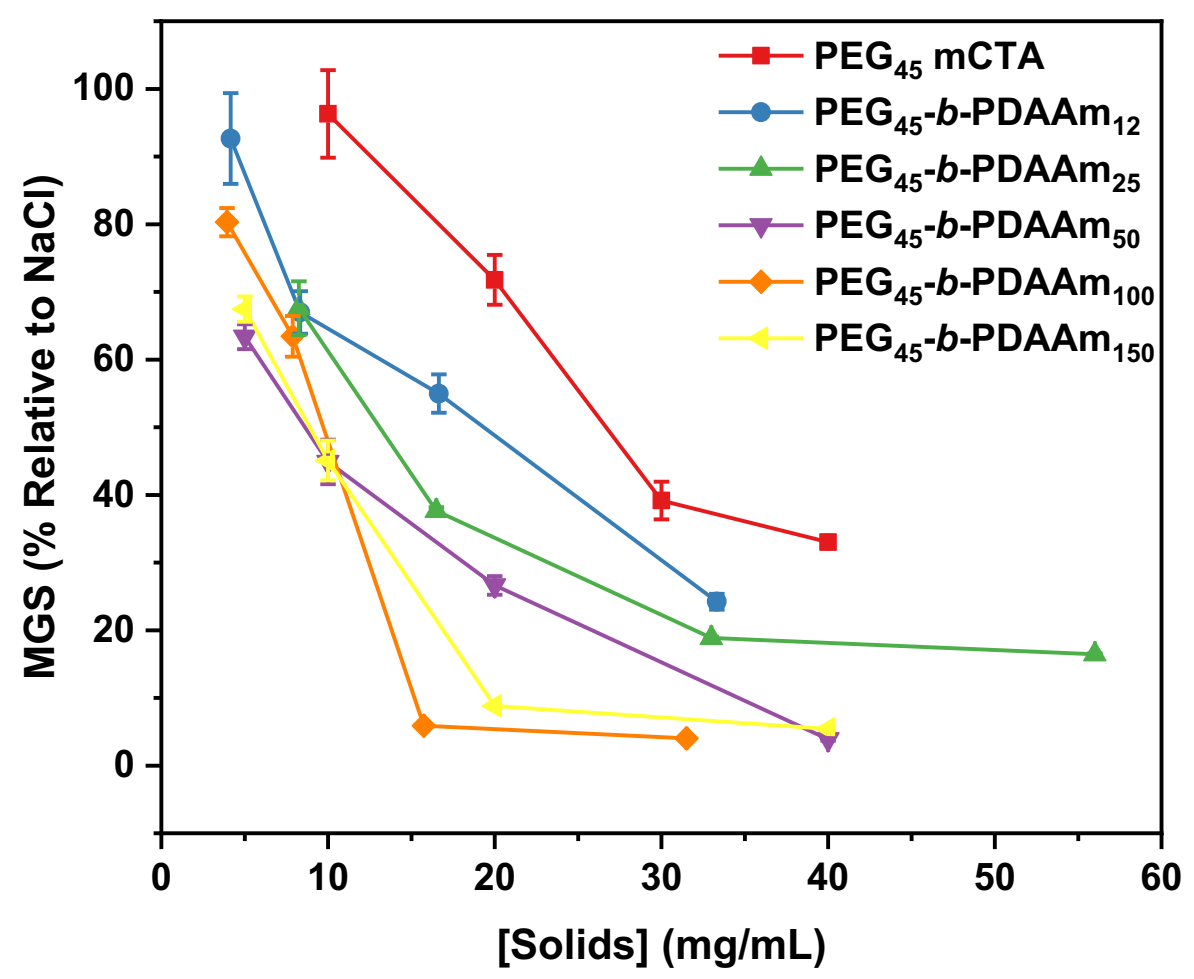

Figure S12. IRI activity summary of $\mathrm{PEG}_{45}-b$-PDAAm $n$ nanoparticles corrected to total mass [=solids] concentration. Error bars are \pm SD from a minimum of three repeats. The percent mean grain size (MGS) was reported relative to saline control $([\mathrm{NaCl}]=0.05 \mathrm{M})$.
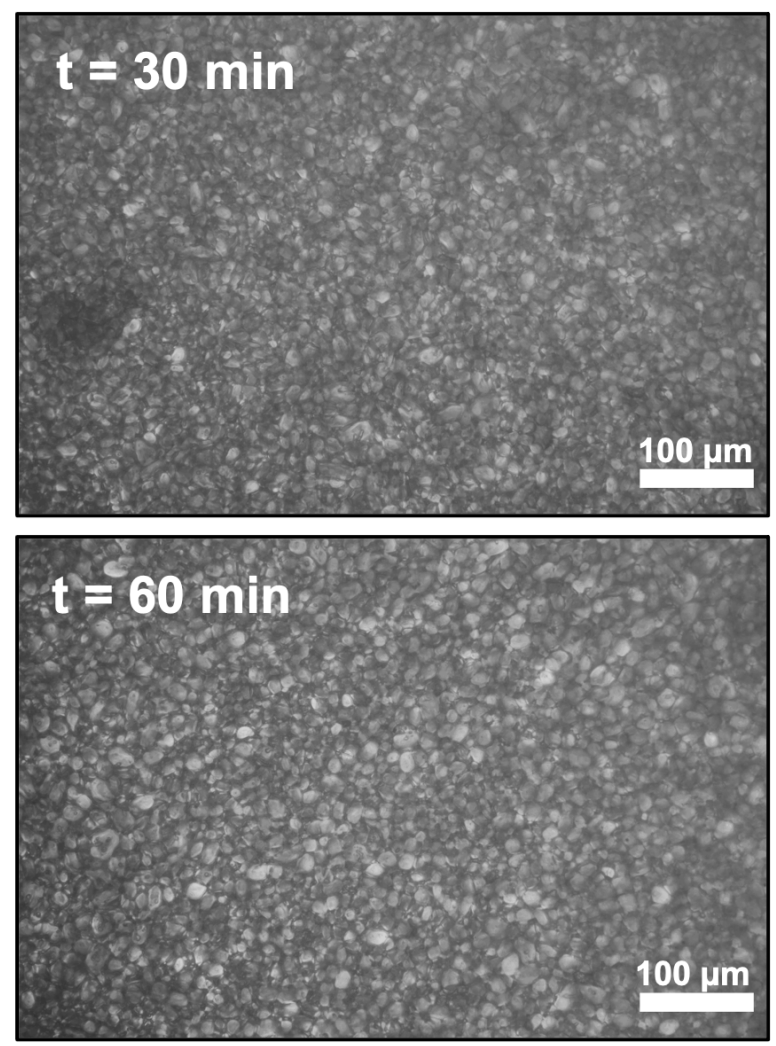

Figure S13. Example cryomicrographs of ice wafers from the 'splat' assay of $\mathrm{PEG}_{45}-b$ PDAAm $_{100}$ block copolymer vesicles, $[\mathrm{PEG}]=10 \mathrm{mg} \cdot \mathrm{mL}^{-1}$ at $\mathrm{t}=30$ and 60 mins. 

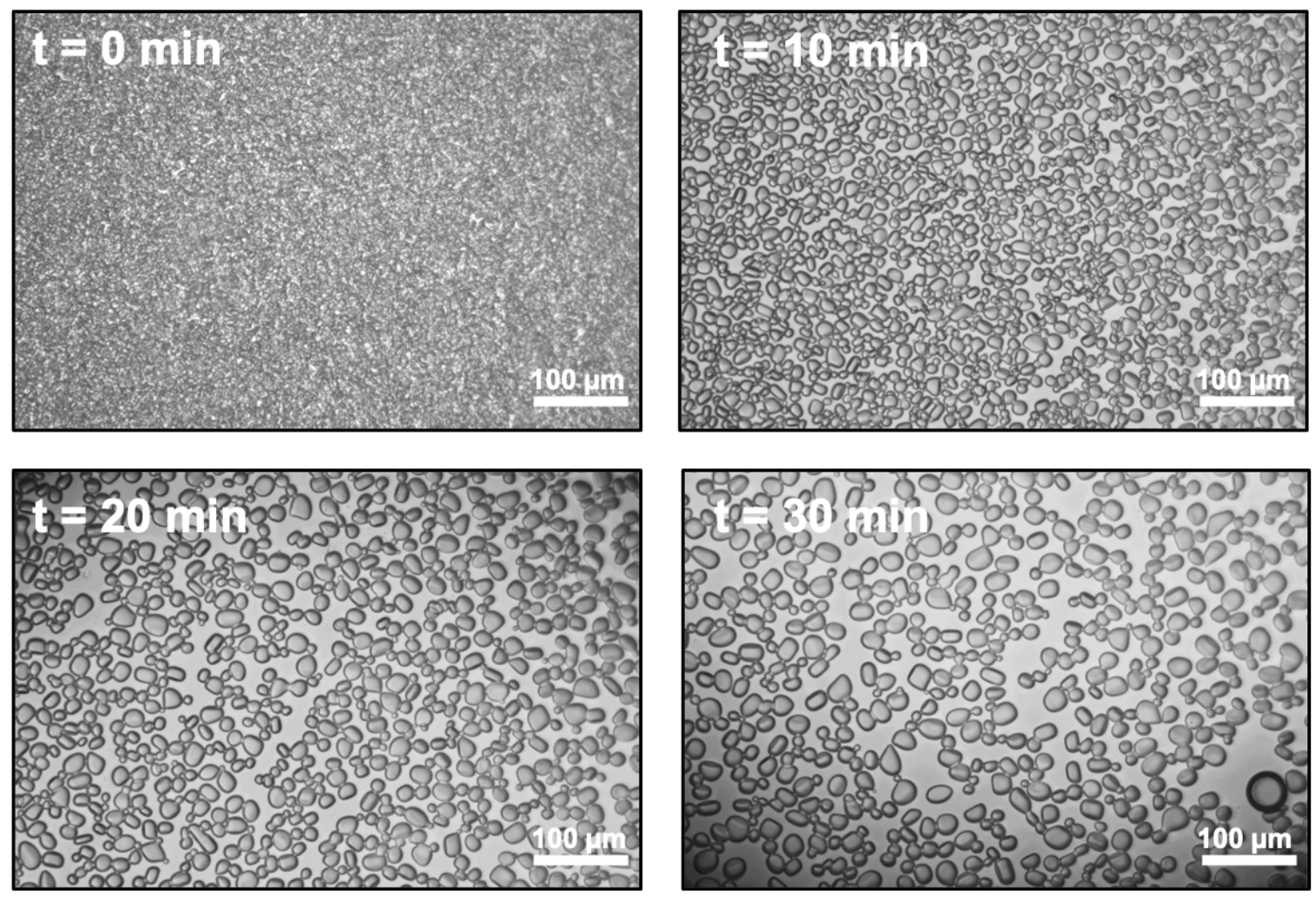

Figure S14. Optical microscopy analysis of ice recrystallization. Micrographs of ice crystals grown in $45 \mathrm{wt} \%$ sucrose plus $10 \mathrm{mg} / \mathrm{mL}$ of $\mathrm{PEG}_{45}$ macro-CTA at $\mathrm{t}=0,10,20$ and $30 \mathrm{mins}$.
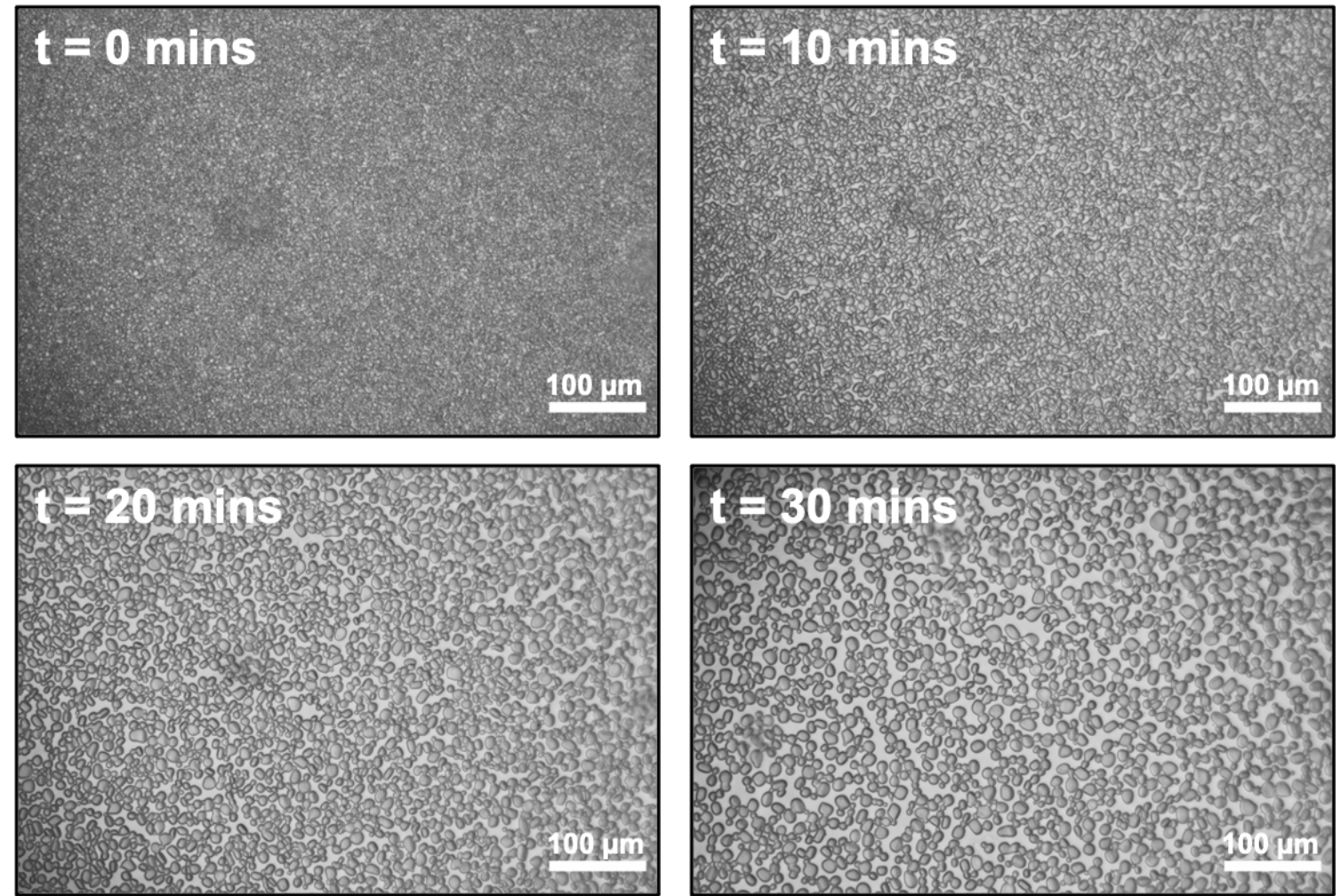

Figure S15. Optical microscopy analysis of ice recrystallization. Micrographs of ice crystals grown in $45 \mathrm{wt} \%$ sucrose plus $10 \mathrm{mg} / \mathrm{mL}$ of $\mathrm{PEG}_{45}-b$-PDAAm 100 block copolymer vesicles at $\mathrm{t}=0,10,20$ and 30 mins. 
A. $\mathrm{PEG}_{45}$ macro-CTA
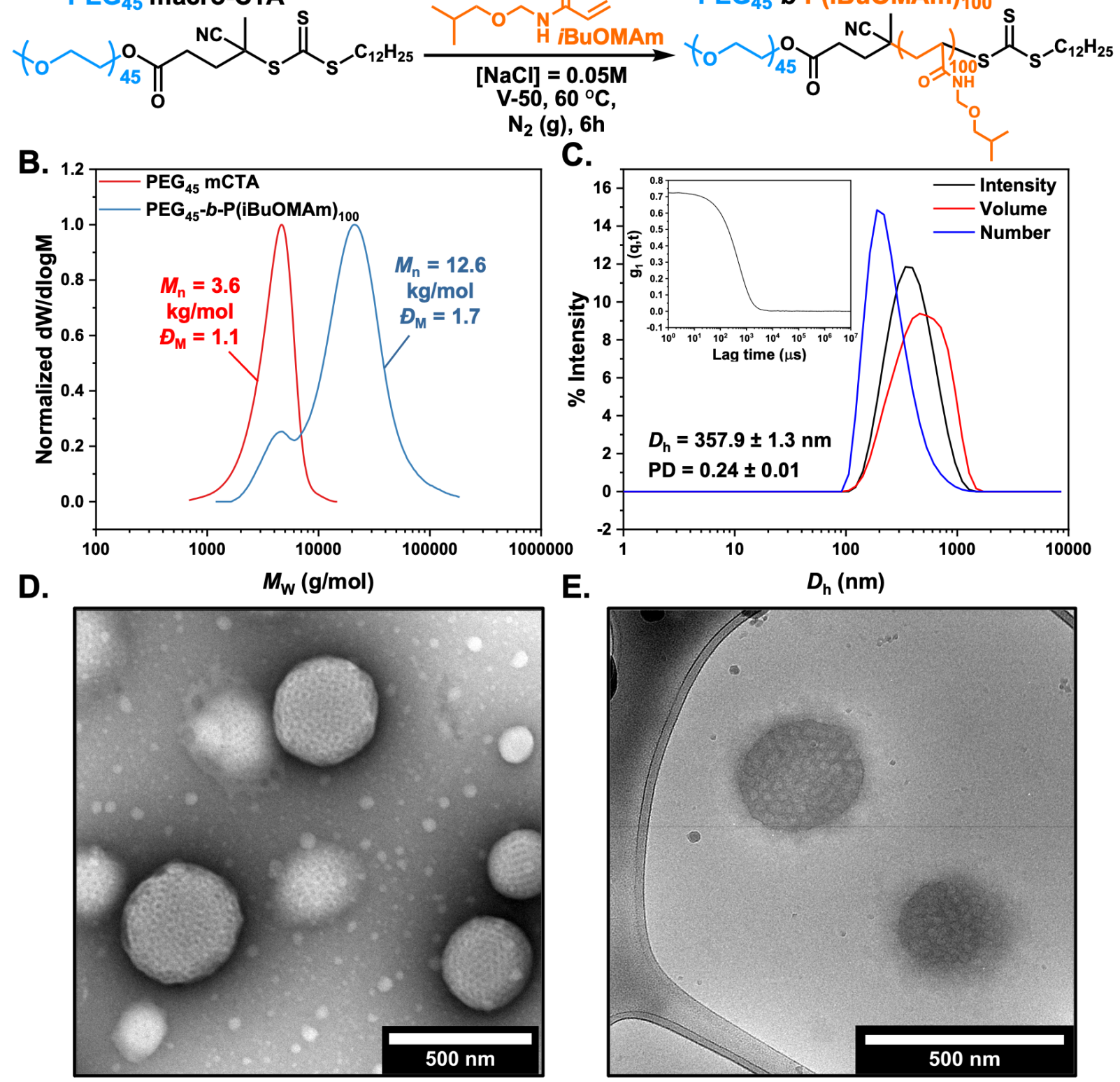

Figure S16. (A) Synthesis of $\mathrm{PEG}_{45}-b$-P $i \mathrm{BuOMAm}_{100}$ diblock copolymer nanoparticles via aqueous RAFT using a PEG $_{45}$ macro-CTA; [solids] $=10 \% \mathrm{w} / \mathrm{w} ;[\mathrm{NaCl}]=0.05 \mathrm{M}$ ]. Characterization of $\mathrm{PEG}_{45}-b$-PiBuOMAm 100 diblock copolymer nanoparticles. (B) Normalized SEC RI molecular weight distributions for PEG 45 macro-CTA (red trace) and $\mathrm{PEG}_{45}-b$ $\mathrm{P} i \mathrm{BuOMAm}_{100}$ (blue trace). $M_{\mathrm{n}}$ and $\bigoplus_{\mathrm{M}}$ values calculated from PS standards using THF $+2 \%$ $\mathrm{v} / \mathrm{v} \mathrm{NEt}_{3}$ as the eluent. (C) Intensity-weighted size distribution along with average $D_{\mathrm{h}}$ and PD values (the error shows the standard deviation from 5 repeat measurements) obtained by DLS; inset: autocorrelation function. (D) Representative dry-state TEM image, stained with $1 \mathrm{wt} \%$ UA solution and (E) cryo-TEM image. 


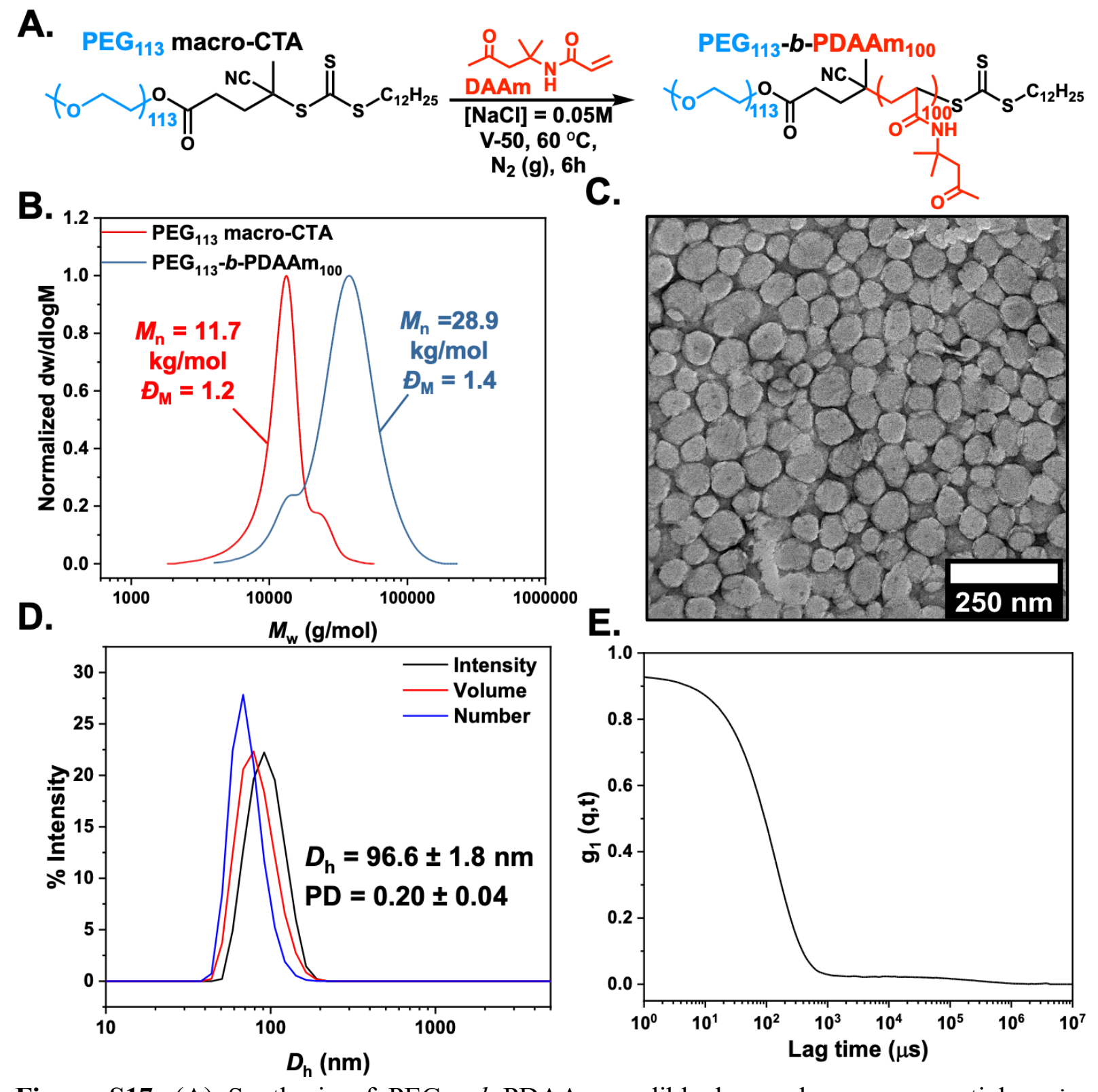

Figure S17. (A) Synthesis of $\mathrm{PEG}_{113}-b-\mathrm{PDAAm}_{100}$ diblock copolymer nanoparticles via aqueous RAFT using a PEG $_{113}$ macro-CTA; [solids] $=10 \% \mathrm{w} / \mathrm{w} ;[\mathrm{NaCl}]=0.05 \mathrm{M}$ ]. Characterization of $\mathrm{PEG}_{113}-b$-PDAAm 100 diblock copolymer nanoparticles. (B) Normalized SEC RI molecular weight distributions for $\mathrm{PEG}_{113}$ macro-CTA (red trace) and $\mathrm{PEG}_{113}-b$ PDAAm 100 (blue trace). $M_{\mathrm{n}}$ and $\bigoplus_{\mathrm{M}}$ values calculated from PMMA standards using DMF + $5 \mathrm{mM} \mathrm{NH}_{4} \mathrm{BF}_{4}$ as the eluent. (C) Representative dry-state TEM image, stained with $1 \mathrm{wt} \% \mathrm{UA}$ solution. (D) Intensity-weighted size distribution along with average $D_{\mathrm{h}}$ and PD values (the error shows the standard deviation from 5 repeat measurements) and (E) autocorrelation function obtained by DLS. 

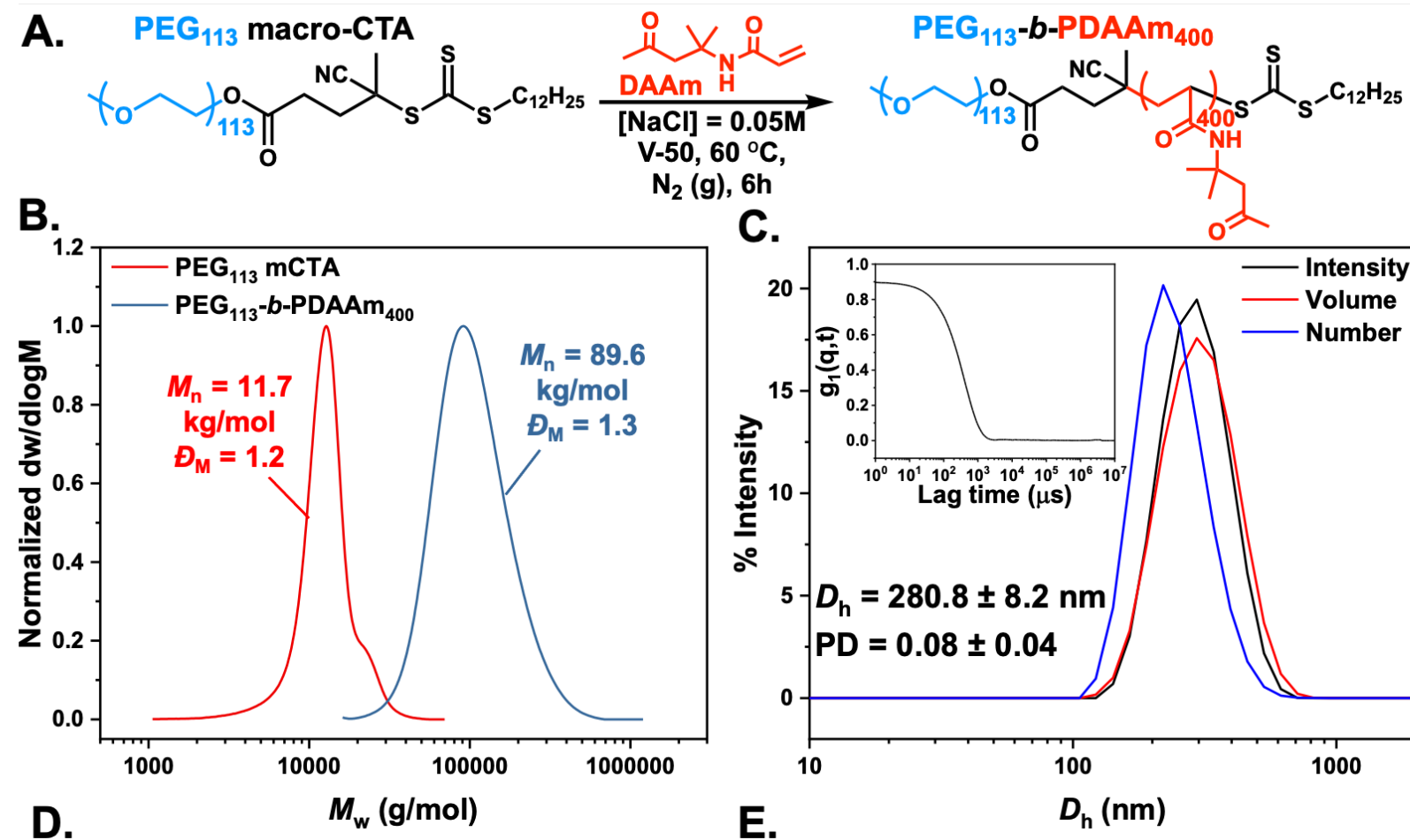

C.

o
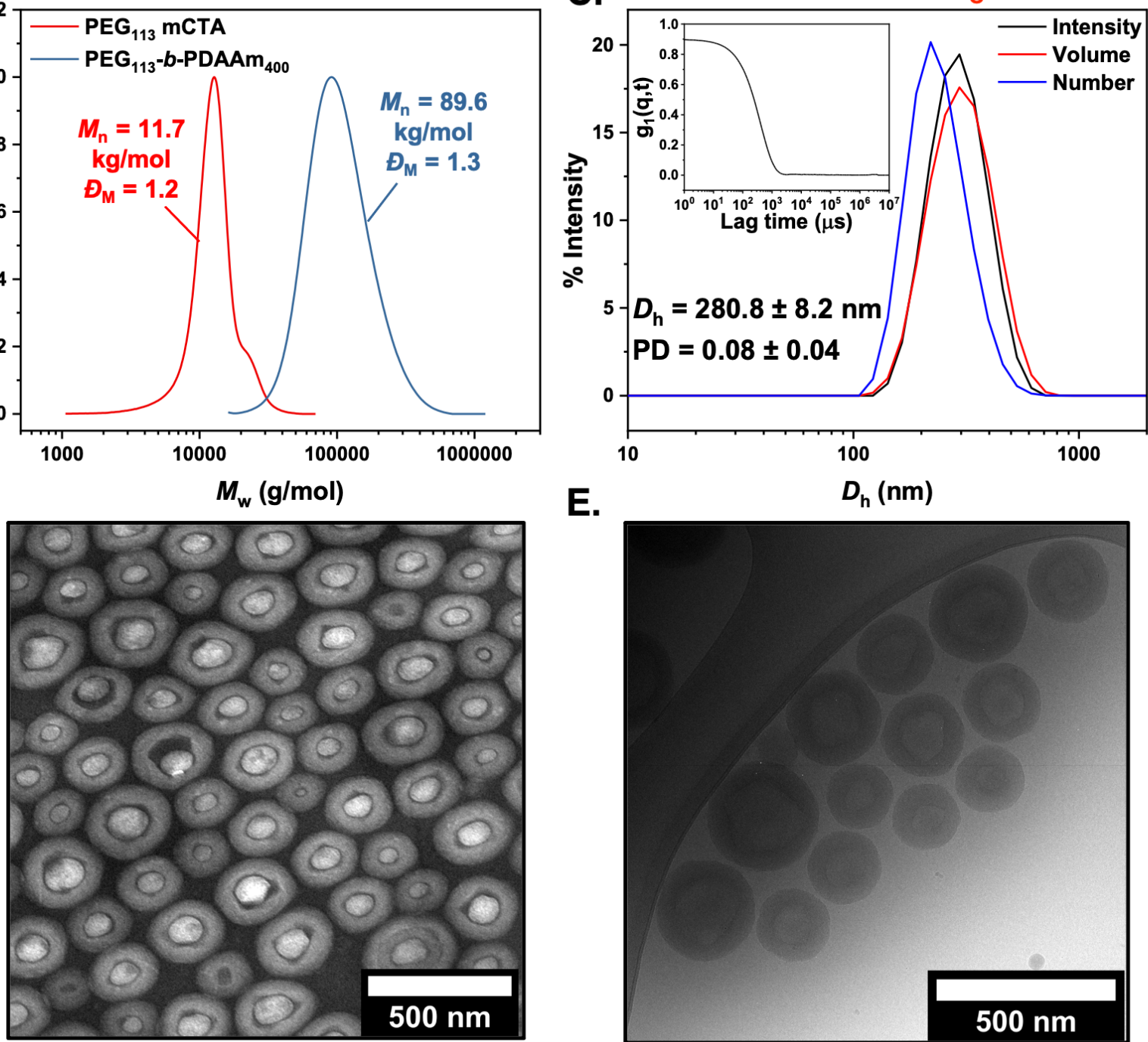

E.

$D_{\mathrm{h}}(\mathrm{nm})$

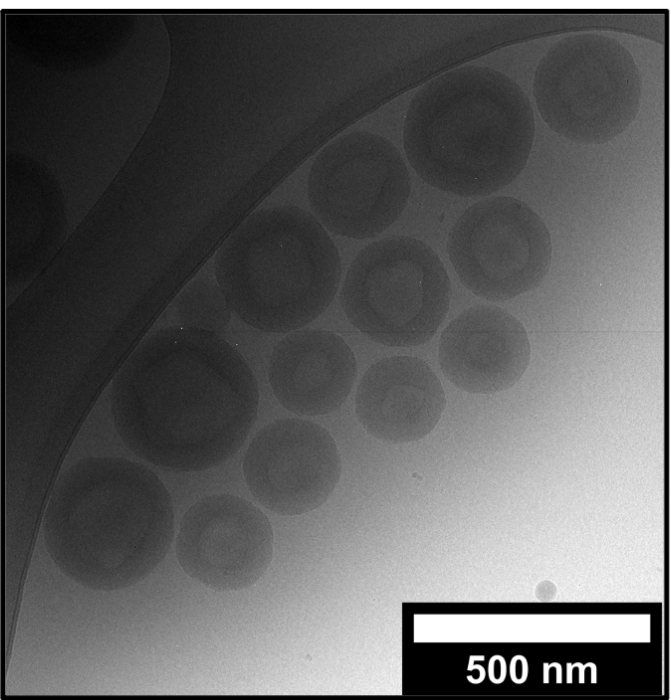

Figure S18. (A) Synthesis of $\mathrm{PEG}_{113}-b-\mathrm{PDAAm}_{400}$ diblock copolymer nanoparticles via aqueous RAFT using a $\mathrm{PEG}_{113}$ macro-CTA; [solids] $=10 \% \mathrm{w} / \mathrm{w} ;[\mathrm{NaCl}]=0.05 \mathrm{M}$ ]. Characterization of $\mathrm{PEG}_{113}-b$-PDAAm 400 diblock copolymer vesicles. (B) Normalized SEC RI molecular weight distributions for $\mathrm{PEG}_{113}$ macro-CTA (red trace) and $\mathrm{PEG}_{113}-b$-PDAAm 400 (blue trace). $M_{\mathrm{n}}$ and $\bigoplus_{\mathrm{M}}$ values calculated from PMMA standards using DMF $+5 \mathrm{mM} \mathrm{NH}_{4} \mathrm{BF}_{4}$ as the eluent. (C) Intensity-weighted size distribution along with average $D_{\mathrm{h}}$ and PD values (the error shows the standard deviation from 5 repeat measurements) obtained by DLS; inset: autocorrelation function. (D) Representative dry-state TEM image, stained with $1 \mathrm{wt} \%$ UA solution and (E) cryo-TEM image. 


\section{Supporting Characterization Data for PVP-Based Diblock Copolymer}

\section{Nanoparticles}

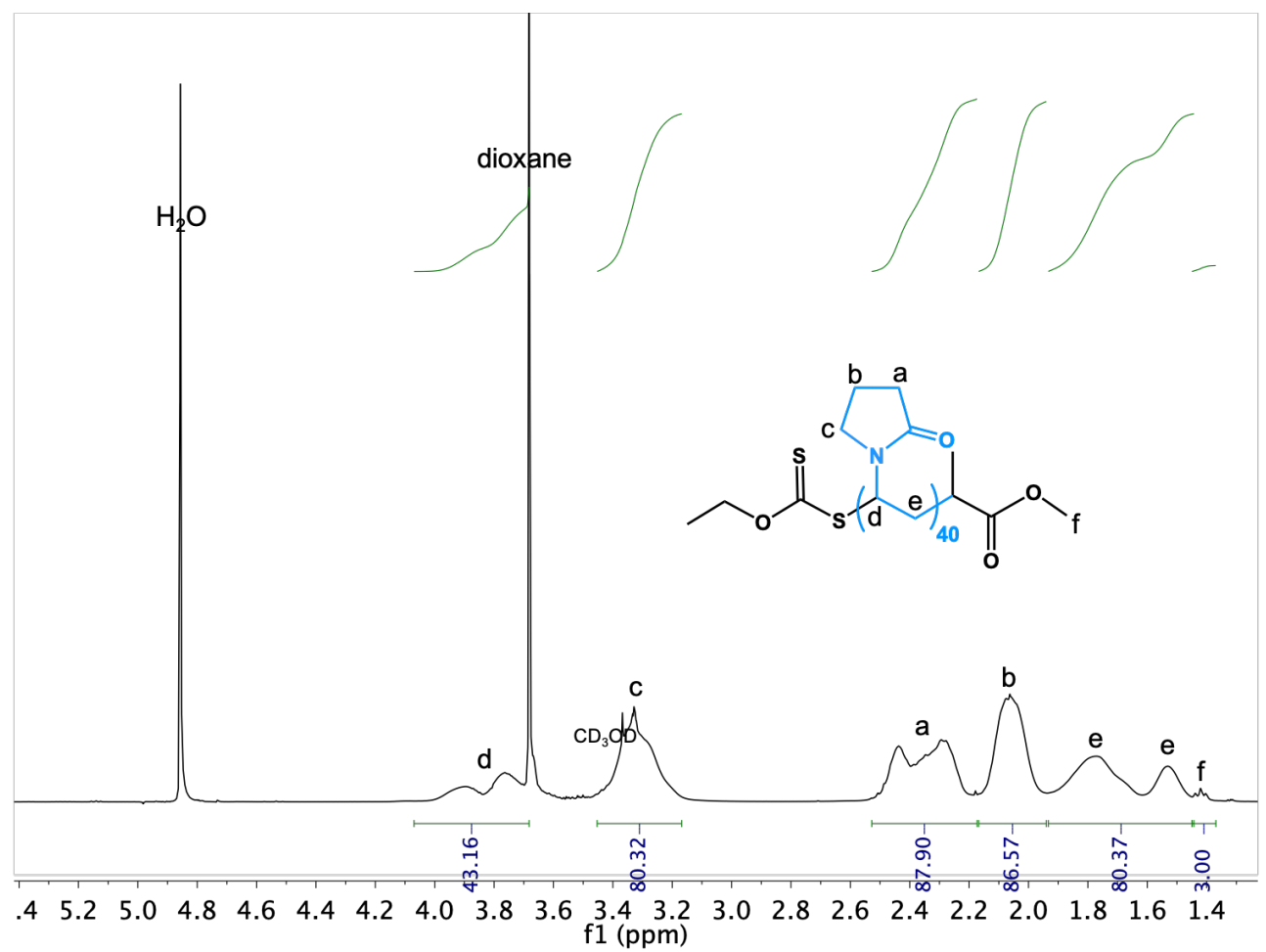

Figure S19. ${ }^{1} \mathrm{H}-\mathrm{NMR}$ spectrum for poly(vinyl pyrrolidinone), $\mathrm{PVP}_{40}$ macro-CTA recorded in methanol- $d_{4}$.

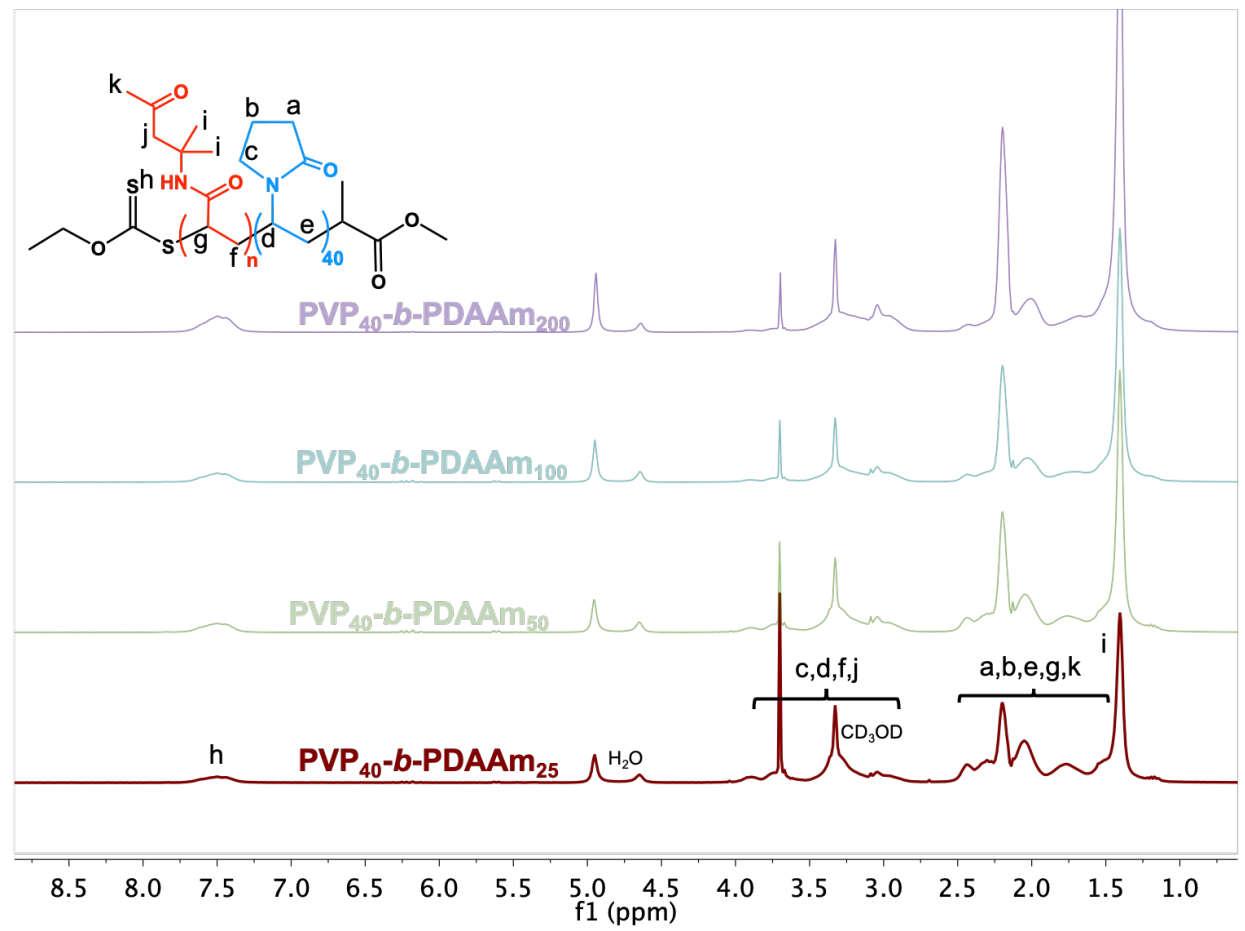

Figure S20. Stacked ${ }^{1} \mathrm{H}-\mathrm{NMR}$ spectra of crude PVP $40-b-\mathrm{PDAAm}_{\mathrm{n}}(\mathrm{n}=25,50,100,200)$ diblock copolymers recorded in methanol- $d_{4}$, showing quantitative monomer consumption $(>98 \%)$. 
Table S2. Molecular characteristics of $\mathrm{PVP}_{40}-b-\mathrm{PDAAm}_{\mathrm{n}}$ diblock copolymers prepared via aqueous RAFT-PISA using different initial [DAAm]/[PVP $40 \mathrm{mCTA}]$ ratios, as determined by ${ }^{1} \mathrm{H}-\mathrm{NMR}$ spectroscopy and SEC analysis.

\begin{tabular}{|c|c|c|c|c|}
\hline$[$ DAAm $] /\left[P_{40}\right.$ mCTA] & $\%$ Conv. $^{a}$ & $M_{\mathrm{n}, \text { theo }}(\mathrm{kDa})^{b}$ & $M_{\mathrm{n}, \operatorname{SEC}}(\mathbf{k D a})^{c}$ & $\boldsymbol{\oplus}_{\mathrm{M}, \mathrm{SEC}^{c}}$ \\
\hline 0 & -------- & 4.7 & 4.6 & 1.3 \\
\hline 25 & $>98$ & 8.8 & 11.3 & 3.1 \\
\hline 50 & $>97$ & 13.1 & 15.8 & 8.9 \\
\hline 100 & $>98$ & 22.5 & 26.1 & 14.5 \\
\hline 200 & $>99$ & 38.4 & 41.3 & 13.7 \\
\hline
\end{tabular}

${ }^{a}$ Monomer conversion calculated from ${ }^{1} \mathrm{H}$-NMR spectroscopy in methanol- $d_{4} \cdot{ }^{b}$ Calculated from conversion. ${ }^{c} M_{\mathrm{n}}$ and $\bigoplus_{\mathrm{M}}$ values calculated from PMMA standards using DMF $+5 \mathrm{mM} \mathrm{NH}_{4} \mathrm{BF}_{4}$ as the eluent.

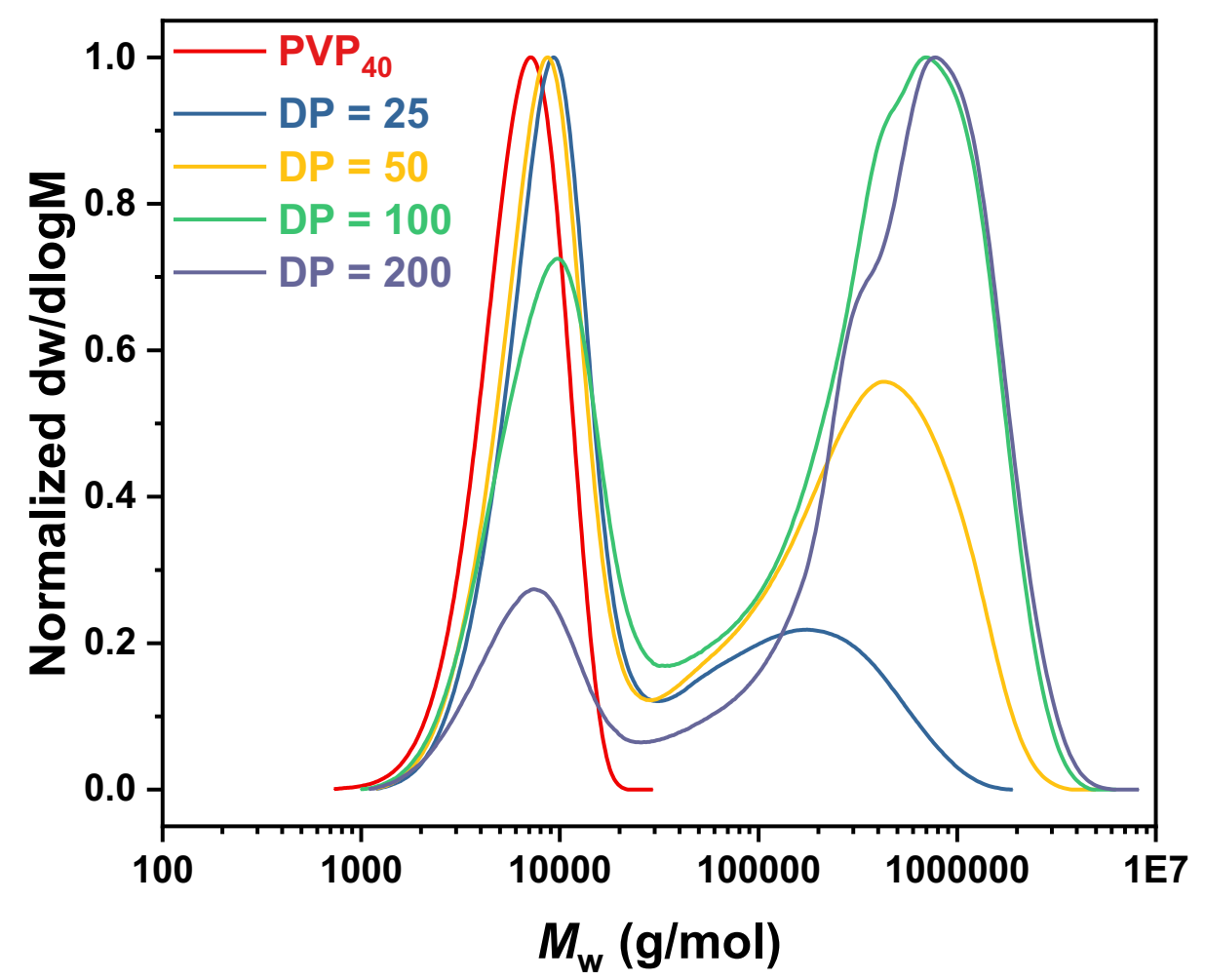

Figure S21. Normalized SEC RI molecular weight distributions for $\mathrm{PVP}_{40}-b-\mathrm{PDAAm}_{\mathrm{n}}(\mathrm{n}=$ $25,50,100,200)$ diblock copolymers before purification (Figure S22) using DMF $+5 \mathrm{mM}$ $\mathrm{NH}_{4} \mathrm{BF}_{4}$ as the eluent. 


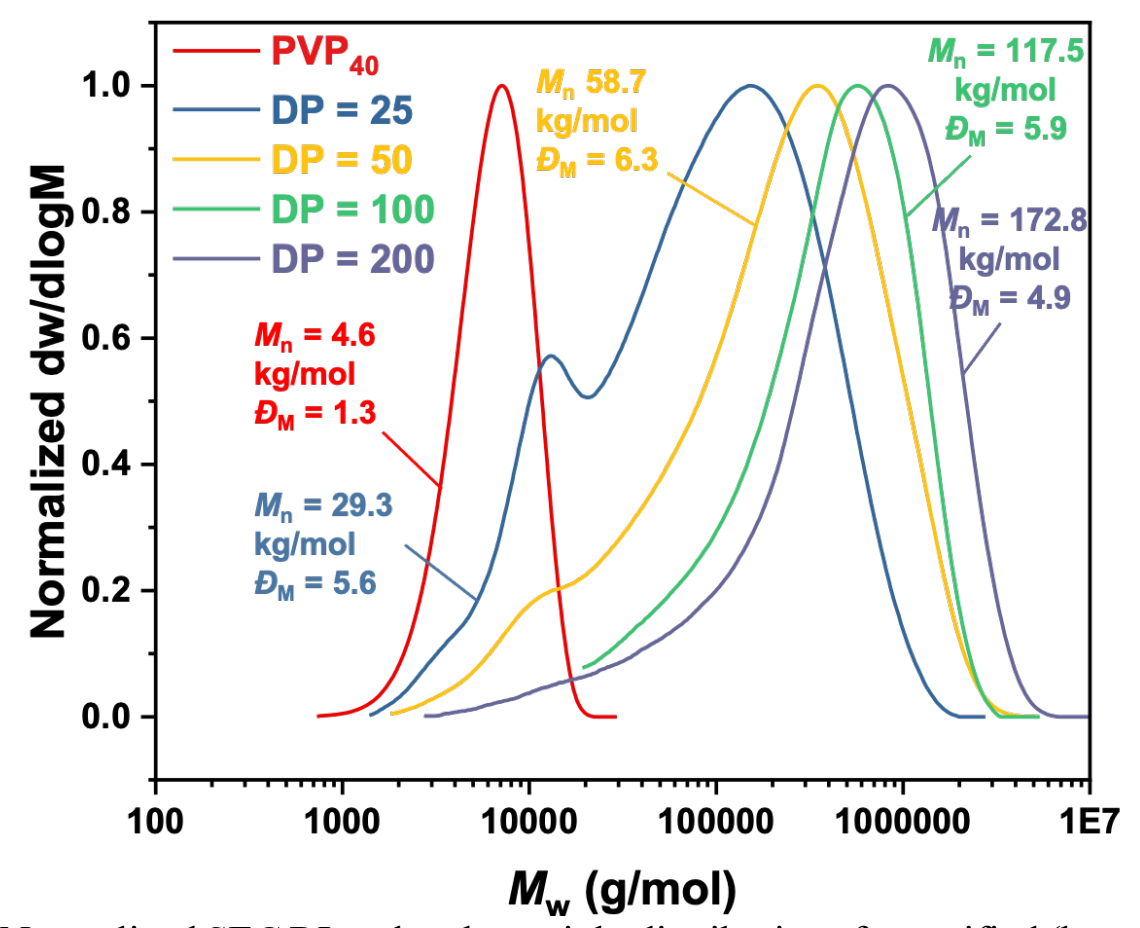

Figure S22. Normalized SEC RI molecular weight distributions for purified (by centrifugation) $\mathrm{PVP}_{40}-b-\mathrm{PDAAm}_{\mathrm{n}}(\mathrm{n}=25,50,100,200)$ diblock copolymers using DMF $+5 \mathrm{mM} \mathrm{NH}_{4} \mathrm{BF}_{4}$ as the eluent after complete removal of $\mathrm{PVP}_{40}$ macro-CTA via multiple centrifugationresuspension cycles. $M_{\mathrm{n}}$ and $\bigoplus_{\mathrm{M}}$ values calculated from PMMA standards using DMF $+5 \mathrm{mM}$ $\mathrm{NH}_{4} \mathrm{BF}_{4}$ as the eluent.
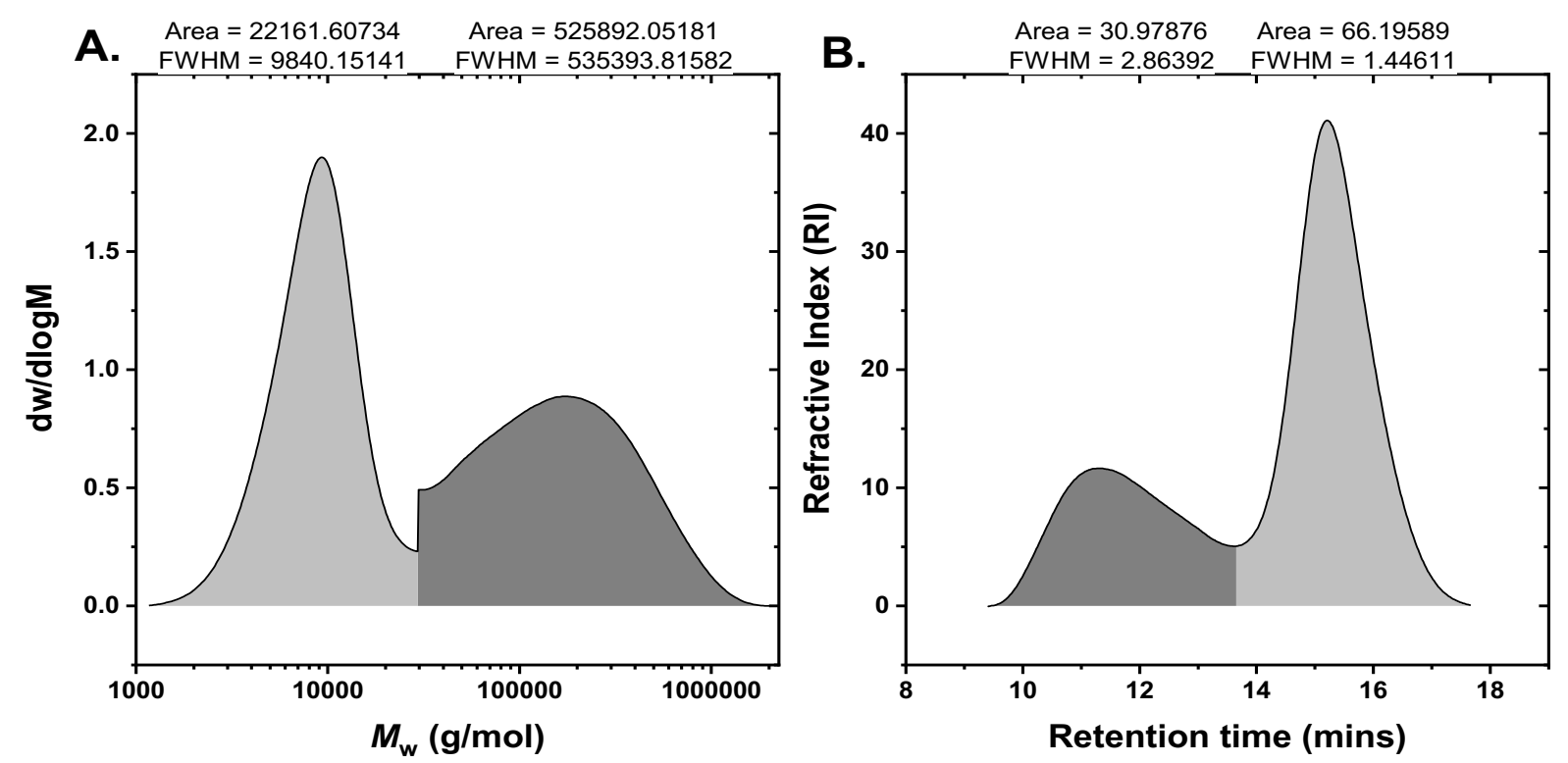

Figure S23. SEC RI distributions for $\mathrm{PVP}_{40}-b$-PDAAm 25 crude diblock copolymer using DMF $+5 \mathrm{mM} \mathrm{NH}_{4} \mathrm{BF}_{4}$ as the eluent. (A) Normalized SEC RI molecular weight distributions. (B) refractive index verses retention time. Area under the curves and FWHM (shown above the peaks) are determined between the same coordinates as the $M_{\mathrm{n}}$ and $\emptyset_{\mathrm{M}}$ calculations; dark grey area: chain extended $\mathrm{PVP}_{40}$ macro-CTA, light grey area: unconsumed $\mathrm{PVP}_{40}$ macro-CTA. 

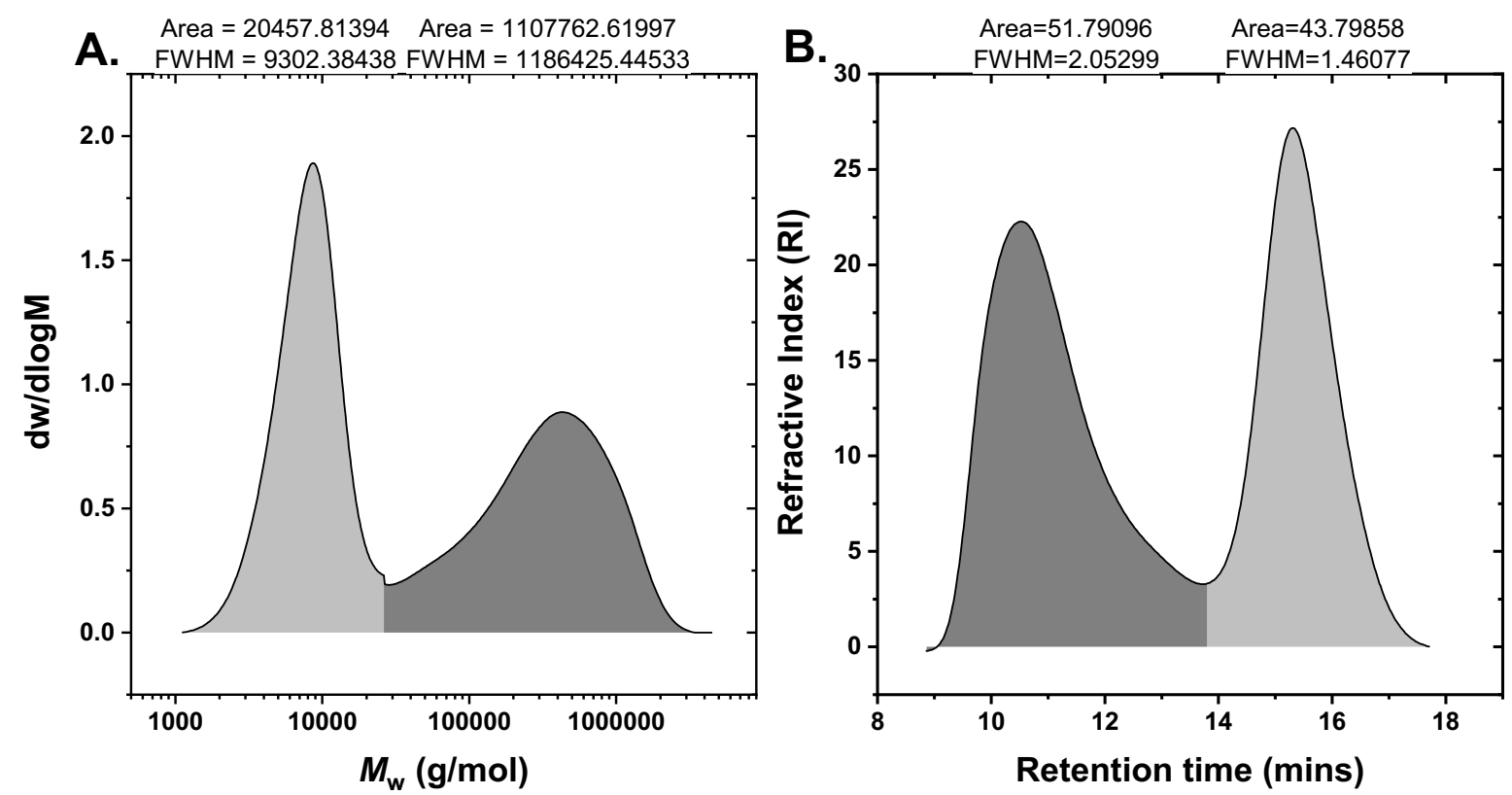

Figure S24. SEC RI distributions for $\mathrm{PVP}_{40}-b-\mathrm{PDAAm}_{50}$ crude diblock copolymer using $\mathrm{DMF}+5 \mathrm{mM} \mathrm{NH}_{4} \mathrm{BF}_{4}$ as the eluent. (A) Normalized SEC RI molecular weight distributions. (B) refractive index verses retention time. Area under the curves and FWHM (shown above the peaks) are determined between the same coordinates as the $M_{\mathrm{n}}$ and $\emptyset_{\mathrm{M}}$ calculations; dark grey area: chain extended $\mathrm{PVP}_{40}$ macro-CTA, light grey area: unconsumed $\mathrm{PVP}_{40}$ macro-CTA.
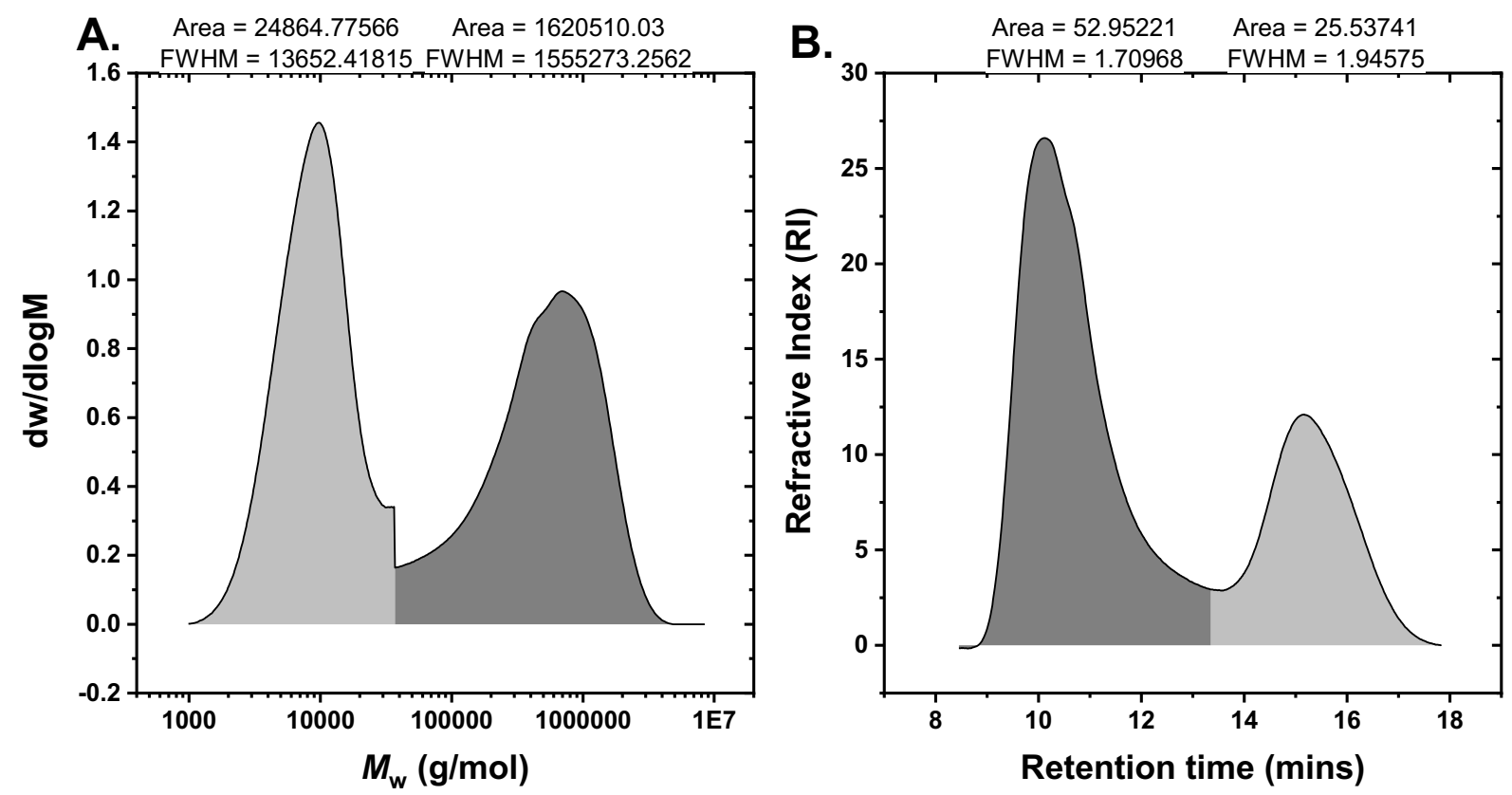

Figure S25. SEC RI distributions for $\mathrm{PVP}_{40}-b$-PDAAm 100 crude diblock copolymer using $\mathrm{DMF}+5 \mathrm{mM} \mathrm{NH}_{4} \mathrm{BF}_{4}$ as the eluent. (A) Normalized SEC RI molecular weight distributions. (B) refractive index verses retention time. Area under the curves and FWHM (shown above the peaks) are determined between the same coordinates as the $M_{\mathrm{n}}$ and $\emptyset_{\mathrm{M}}$ calculations; dark grey area: chain extended $\mathrm{PVP}_{40}$ macro-CTA, light grey area: unconsumed $\mathrm{PVP}_{40}$ macro-CTA. 

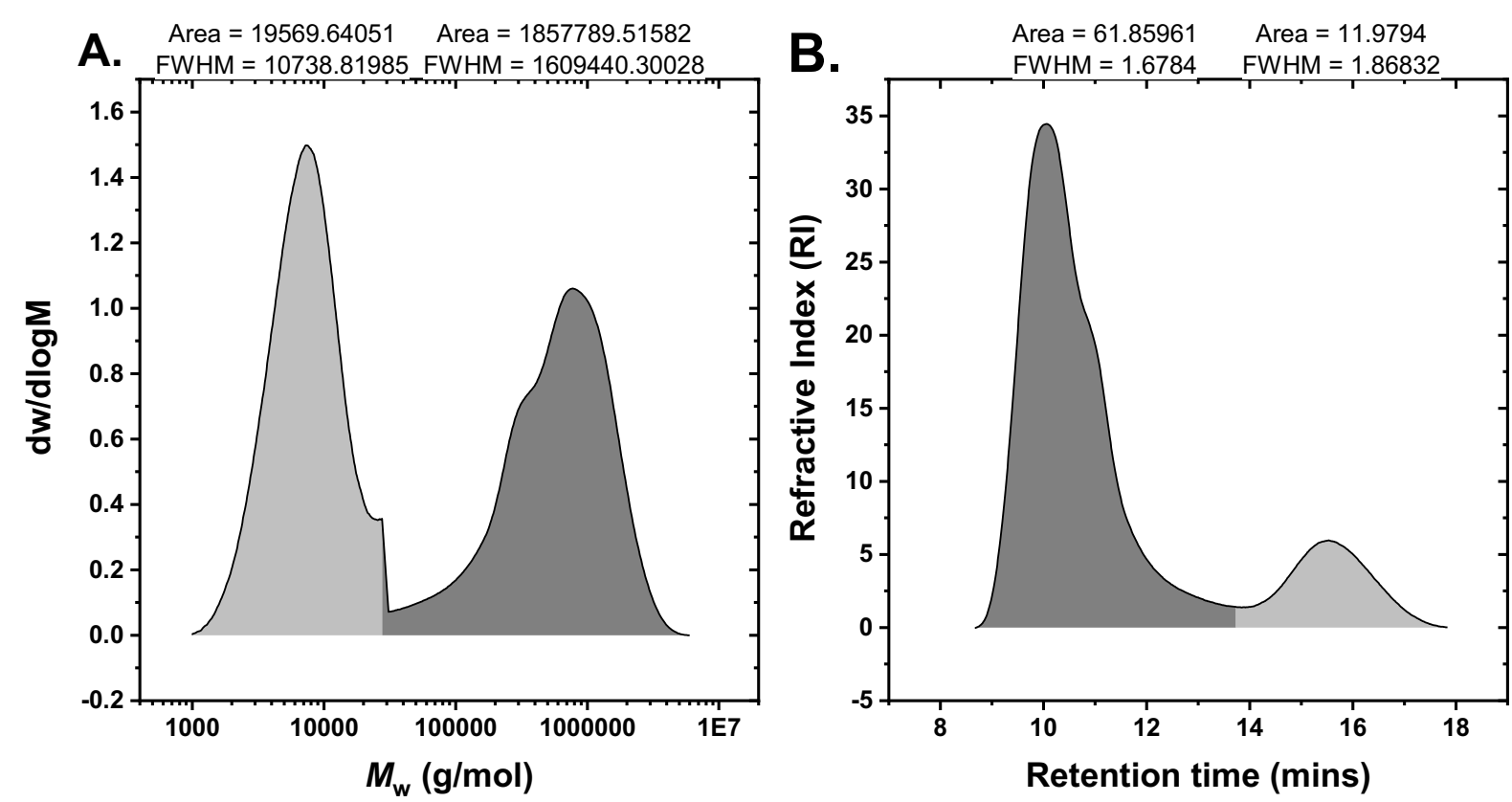

Figure S26. SEC RI distributions for $\mathrm{PVP}_{40}-b$-PDAAm 200 crude diblock copolymer using $\mathrm{DMF}+5 \mathrm{mM} \mathrm{NH}_{4} \mathrm{BF}_{4}$ as the eluent. (A) Normalized SEC RI molecular weight distributions. (B) refractive index verses retention time. Area under the curves and FWHM (shown above the peaks) are determined between the same coordinates as the $M_{\mathrm{n}}$ and $\emptyset_{\mathrm{M}}$ calculations; dark grey area: chain extended $\mathrm{PVP}_{40}$ macro-CTA, light grey area: unconsumed $\mathrm{PVP}_{40}$ macro-CTA.

Table S3. Area under the SEC curves for PVP $\mathrm{PV}_{40} b-\mathrm{PDAAm}_{\mathrm{n}}(\mathrm{n}=25,50,100,200)$ crude diblock copolymer using DMF $+5 \mathrm{mM} \mathrm{NH}_{4} \mathrm{BF}_{4}$ as the eluent, determined between the same coordinates as the $M_{\mathrm{n}}$ and $\bigoplus_{\mathrm{M}}$ calculations; Peak A: unconsumed PVP 40 macro-CTA, Peak B: chain extended $\mathrm{PVP}_{40}$ macro-CTA. For determination of PVP free chains verses particles (for Figure 5 main paper) the values from RI were used.

\begin{tabular}{|c|c|c|c|c|c|c|}
\hline & \multicolumn{3}{|c|}{$\begin{array}{c}\text { Normalized dw/dlogM by } \\
\text { Molecular Weight }\left(\boldsymbol{M}_{\mathbf{w}}\right)\end{array}$} & \multicolumn{3}{c|}{ Refractive Index by Retention } \\
Time
\end{tabular}



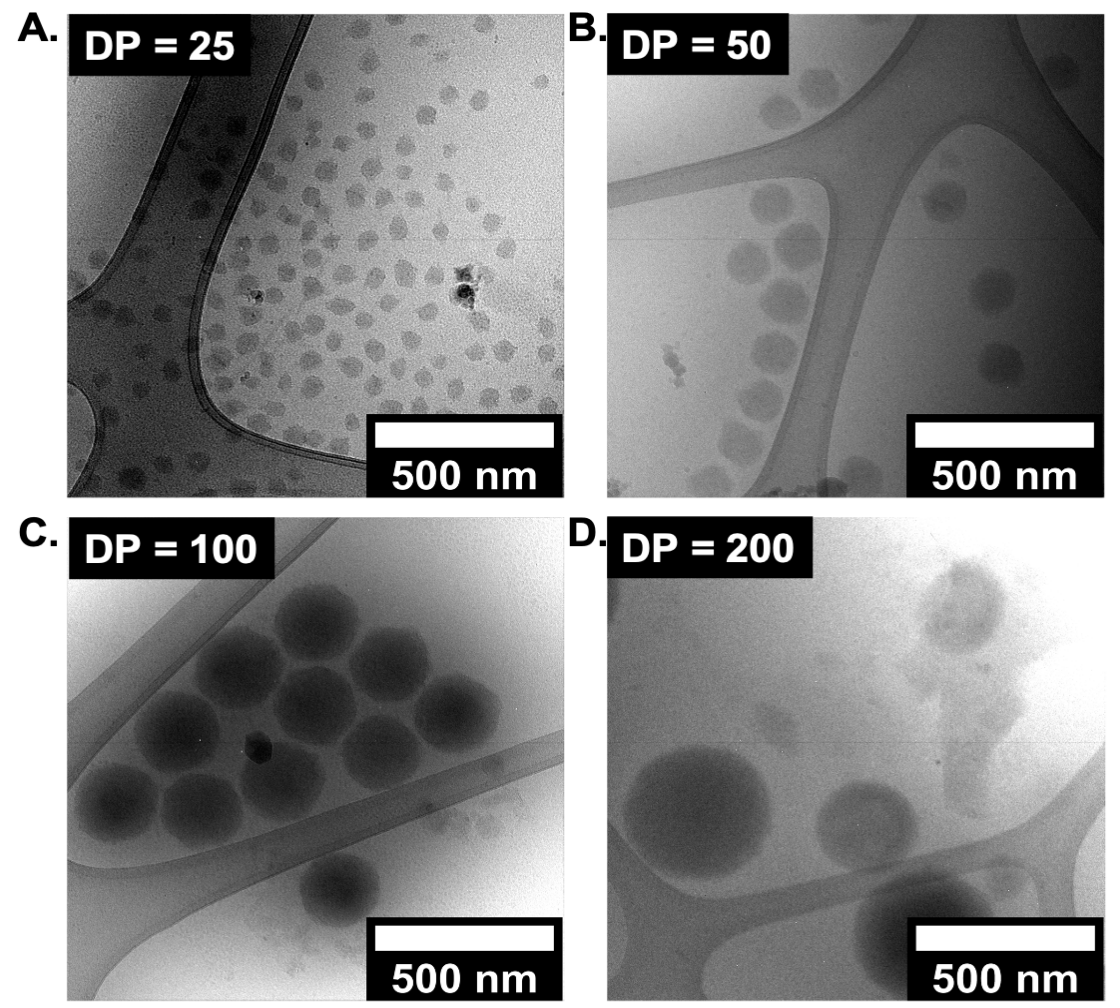

\section{D. $D P=200$}

Figure S27. Representative cryo-TEM images for $\mathrm{PVP}_{40}-b$-PDAAm $\mathrm{n}_{\mathrm{n}}$ diblock copolymer nanoparticles (n = 25 (A), 50 (B), 100 (C) and 200 (D)).

A. $n=25$

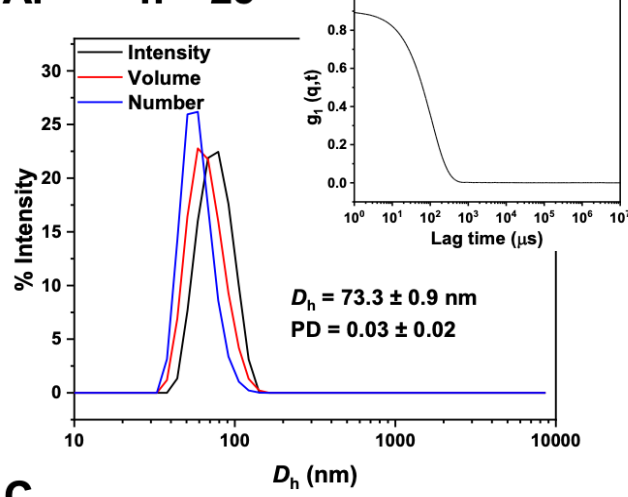

C. $n=100$

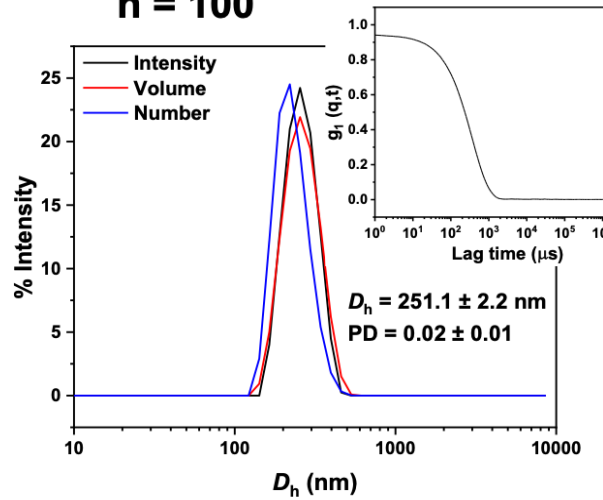

B. $\quad \mathbf{n}=\mathbf{5 0}$
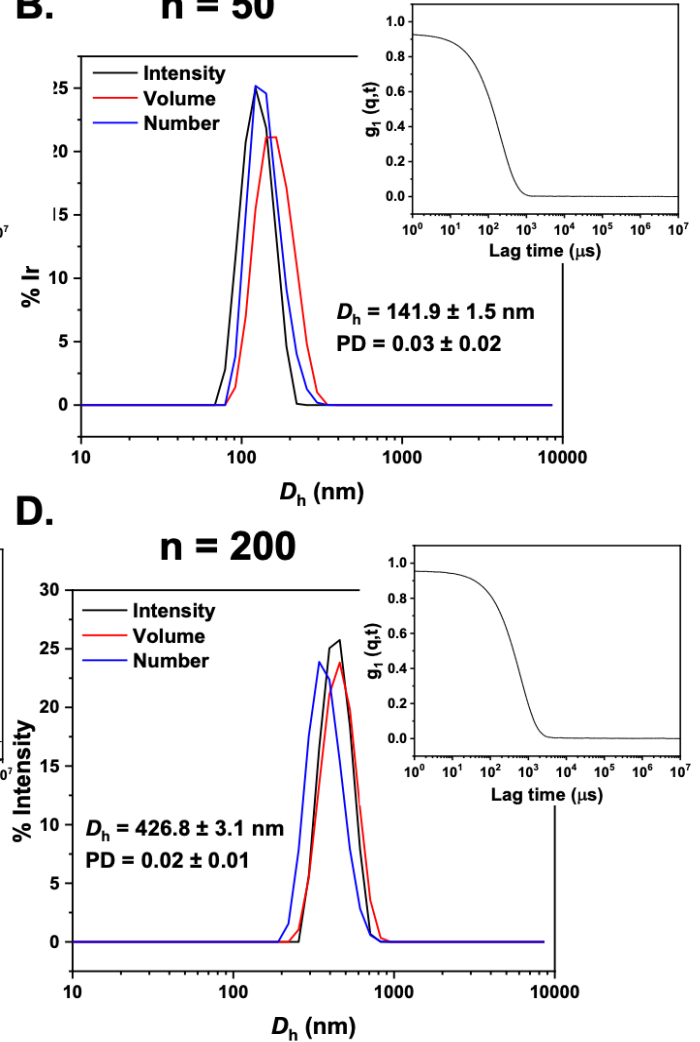

Figure S28. (A) Intensity-weighted size distributions and autocorrelation functions obtained by DLS along with average $D_{\mathrm{h}}$ and PD values for $\mathrm{PVP}_{40}-b-\mathrm{PDAAm}_{\mathrm{n}}(\mathrm{n}=25$ (A), 50 (B), 100 (C) and 200 (D)) diblock copolymer nanoparticles (the error shows the standard deviation from 5 repeat measurements). 


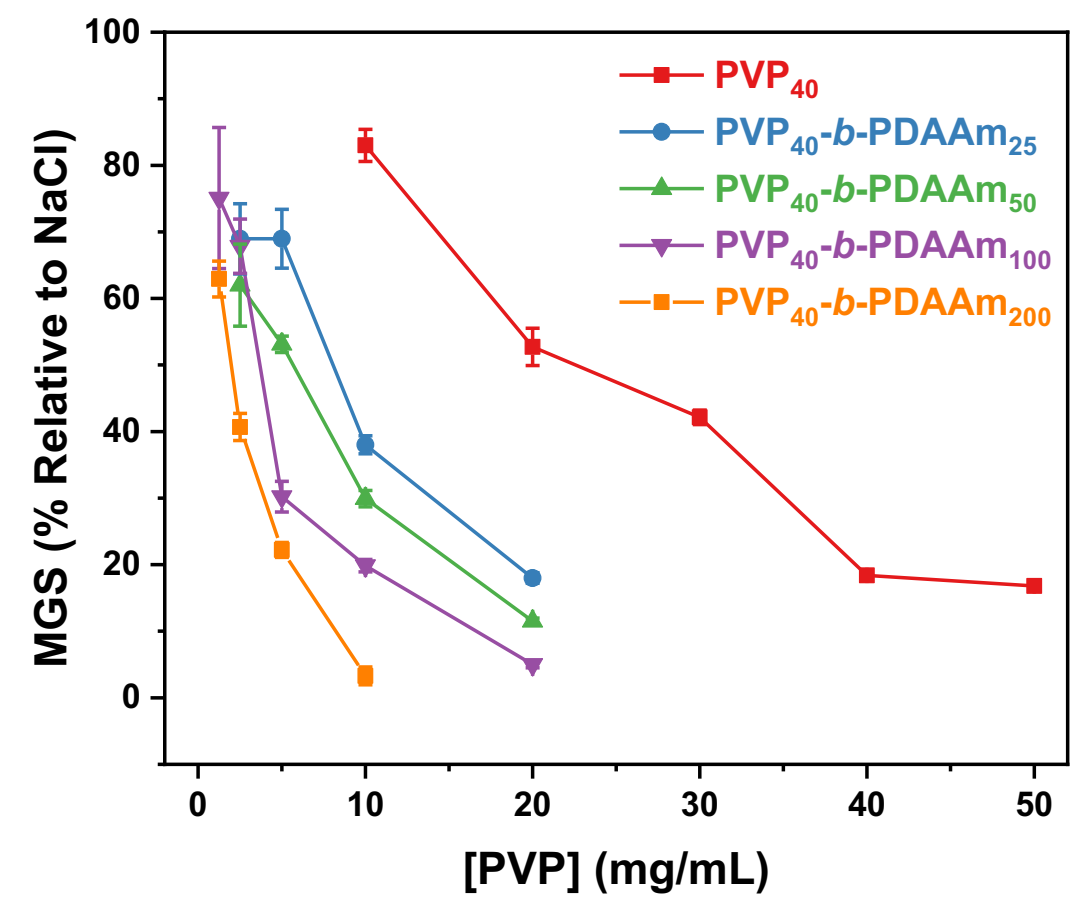

Figure S29. Ice recrystallization inhibition (IRI) activity of $\mathrm{PVP}_{40}-b$-PDAAm $n$ non-purified nanoparticles corrected to total PVP concentration. [PVP] includes a population of non-particle bound chains, hence the particle activity is an underestimate, but is presented as total [PVP]. Purified particle data is in the main paper.

\section{Supporting Characterization Data for PDMAC-Based Diblock Copolymer}

\section{Nanoparticles}

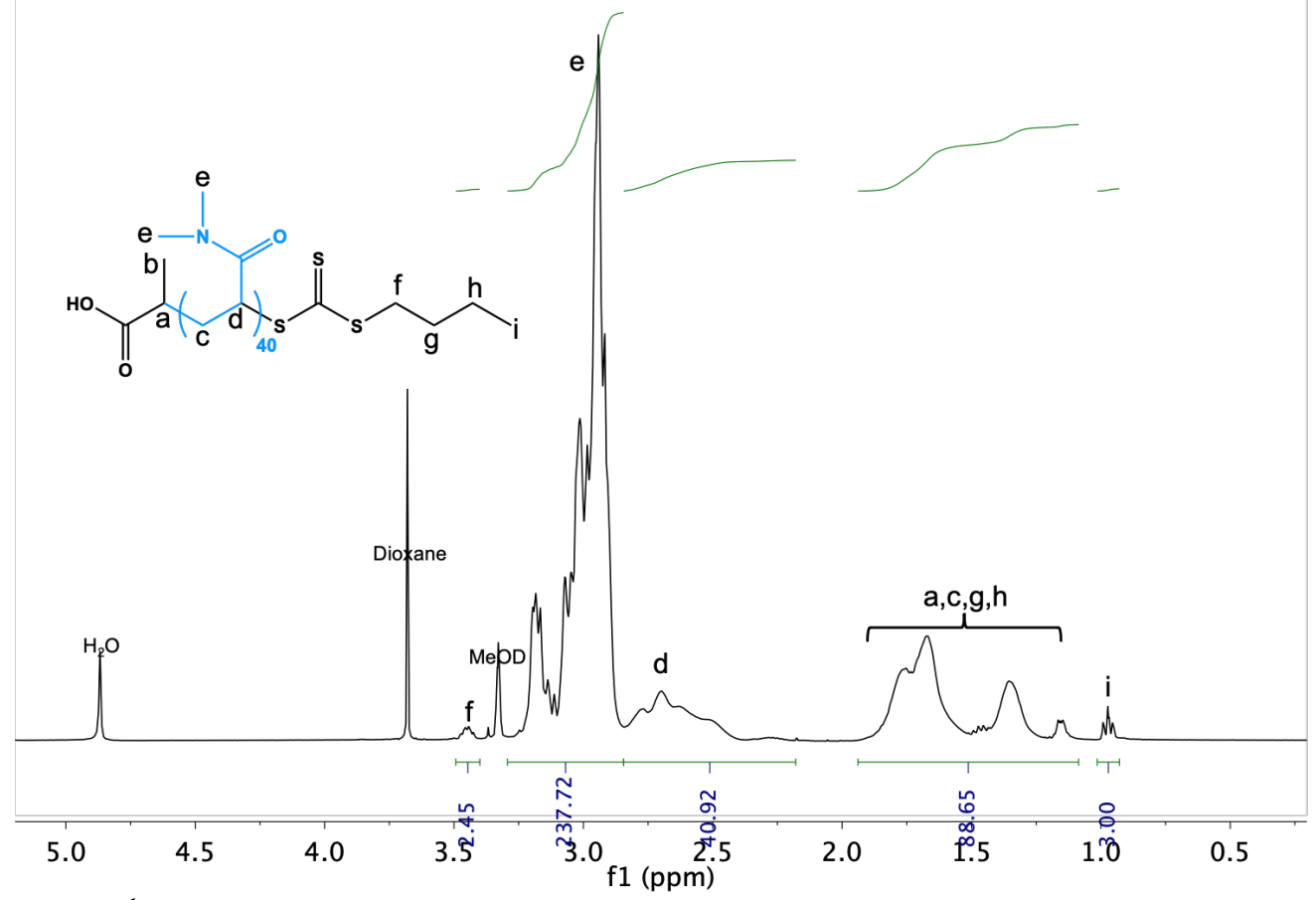

Figure S30. ${ }^{1} \mathrm{H}-\mathrm{NMR}$ spectrum for poly(dimethyl acrylamide), PDMAC 40 macro-CTA recorded in methanol- $d_{4}$. 


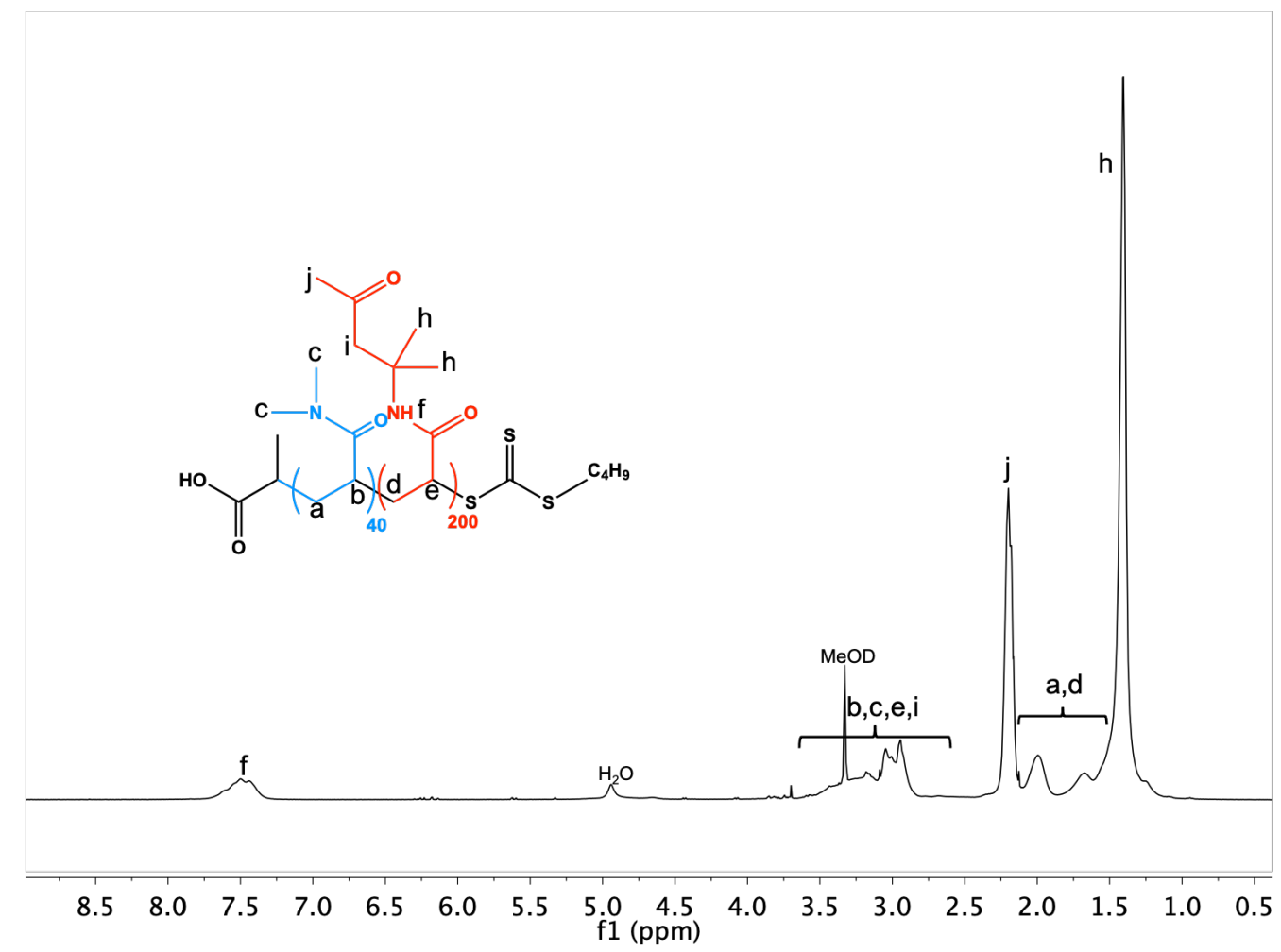

Figure S31. ${ }^{1} \mathrm{H}-\mathrm{NMR}$ spectrum for crude $\mathrm{PDMAC}_{40}-b$-PDAAm 200 diblock copolymer recorded in methanol- $d_{4}$, showing quantitative monomer consumption ( $\left.>99 \%\right)$.

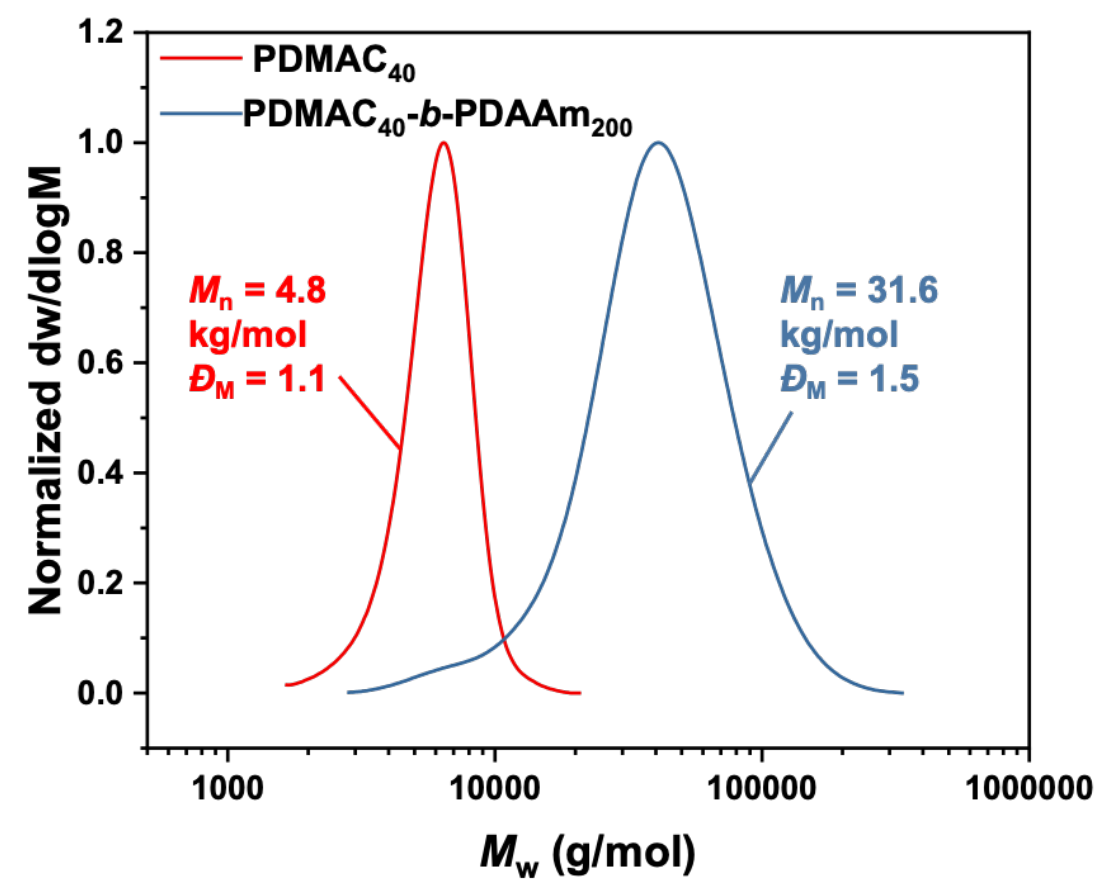

Figure S32. Normalized SEC molecular weight distributions for PDMAC 40 mCTA (red trace) and PDMAC $40-b$-PDAAm 200 (blue trace). $M_{\mathrm{n}}$ and $\bigoplus_{\mathrm{M}}$ values calculated from PMMA standards using DMF $+5 \mathrm{mM} \mathrm{NH}_{4} \mathrm{BF}_{4}$ as the eluent. 

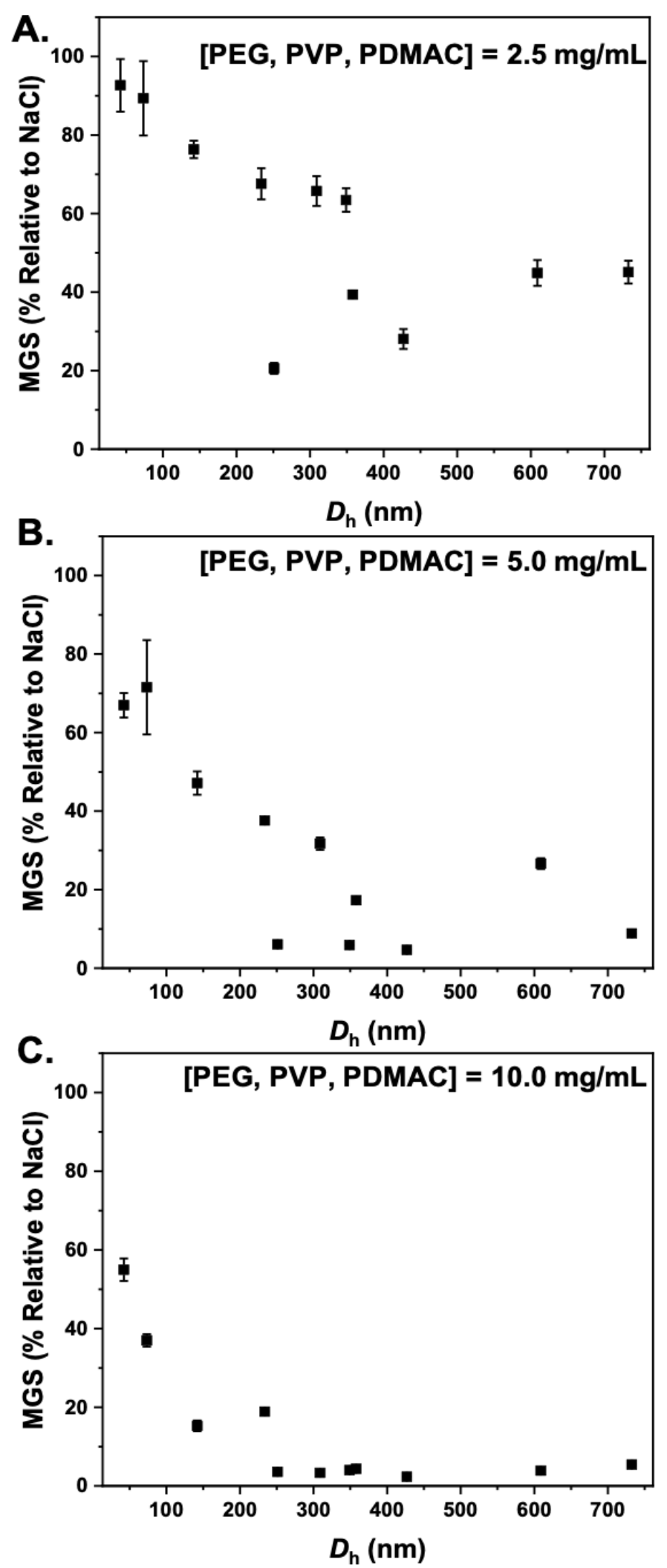

Figure S33. Summary of ice recrystallization inhibition (IRI) activities for $\mathrm{PEG}_{45}, \mathrm{PVP}_{40}$ and PDMAC 40 -coronal nanoparticles verses average hydrodynamic diameter $\left(D_{\mathrm{h}}\right)$ obtained by DLS analysis at $\left[\mathrm{PEG}_{45}, \mathrm{PVP}_{40}, \mathrm{PDMAC}_{40}\right]=2.5(\mathrm{~A}), 5.0(\mathrm{~B})$ and $10 \mathrm{mg} \cdot \mathrm{mL}^{-1}$. Error bars are $\pm \mathrm{SD}$ from a minimum of three repeats. The percent mean grain size (MGS) was reported relative to saline control. 
Supporting Ice Shaping Data/Images
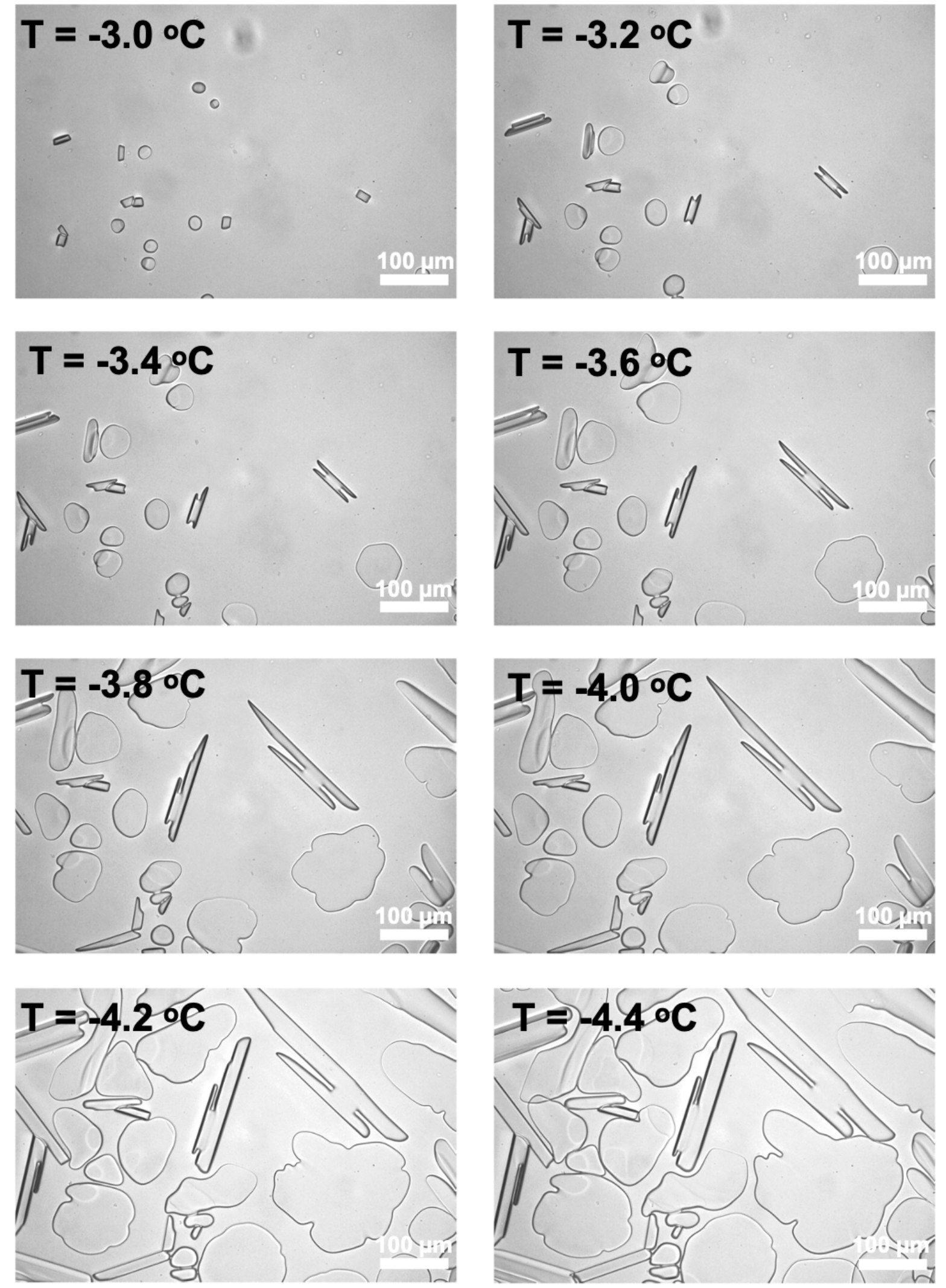

Figure S34. Modified sucrose "sandwich" ice shaping for $5 \mathrm{mg} \cdot \mathrm{mL}^{-1}$ of $\mathrm{PEG}_{45}-b-\mathrm{PDAAm}{ }_{150}$ diblock copolymer vesicles. Needle-shaped crystals are flat disks lying on their side rather than floating and their round basal plane uppermost. 

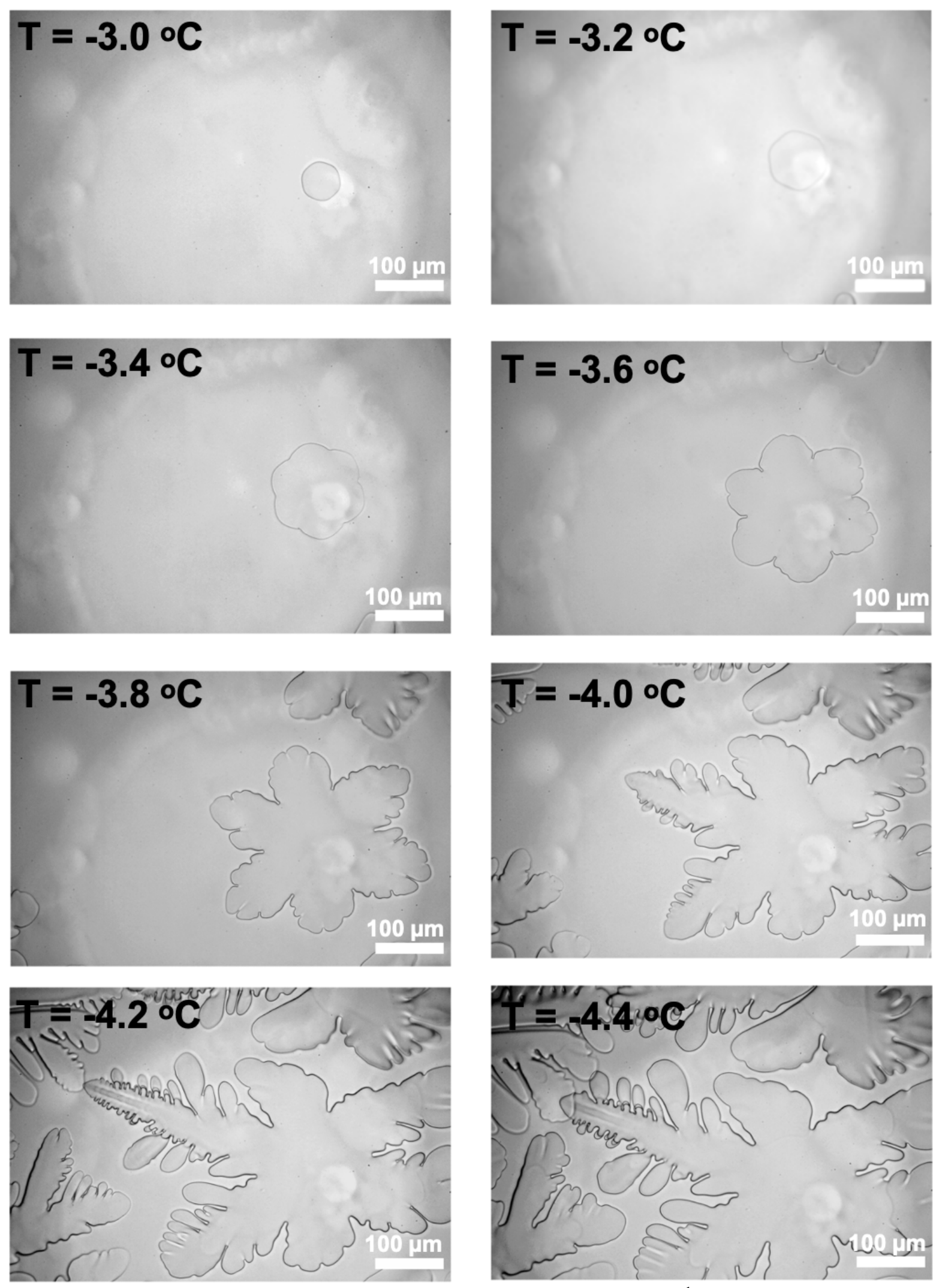

Figure S35. Modified sucrose "sandwich" ice shaping for $5 \mathrm{mg} \cdot \mathrm{mL}^{-1}$ of $\mathrm{PVP}_{40}$ homopolymer. 

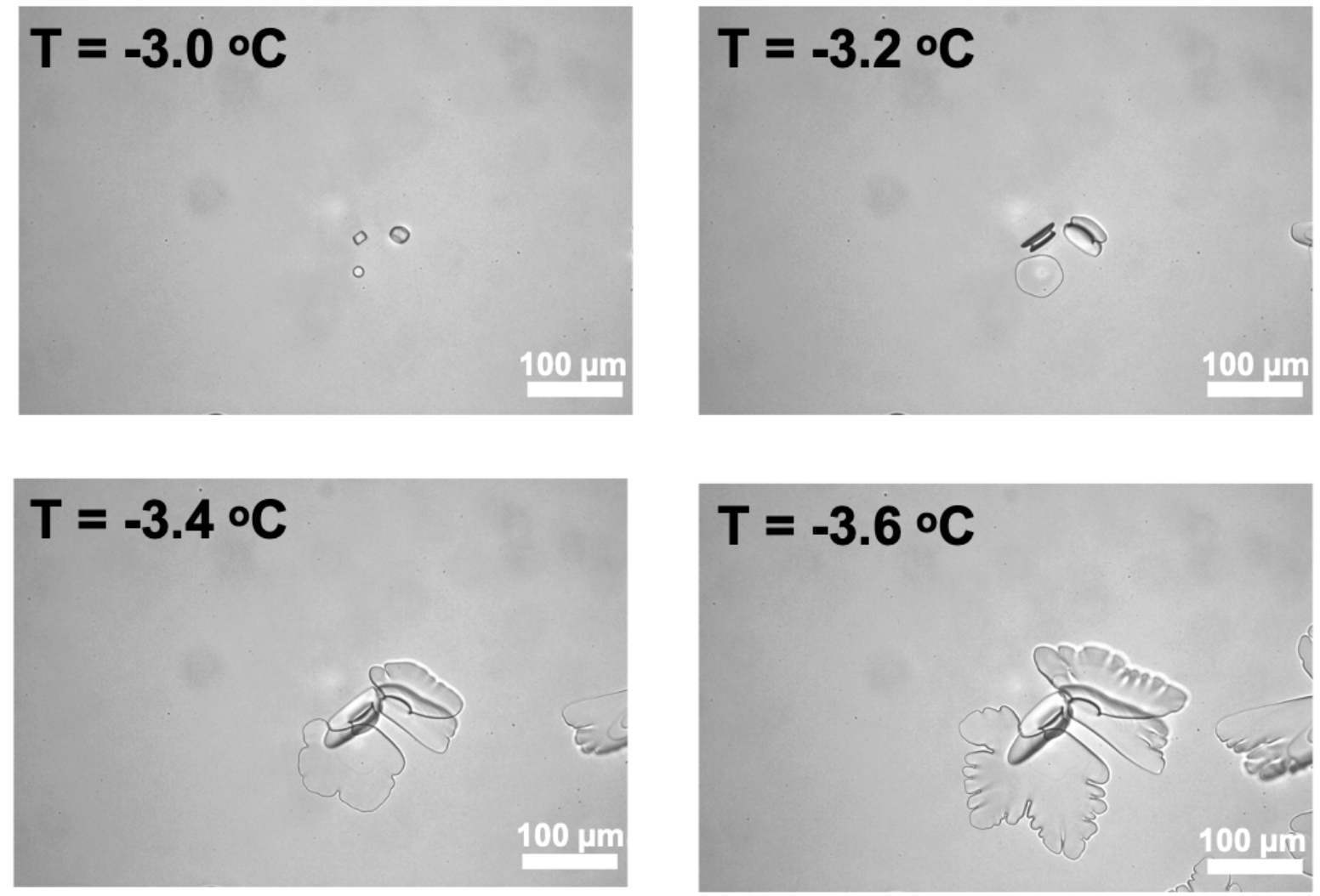

\section{$\mathrm{T}=-3.8^{\circ} \mathrm{C}$}
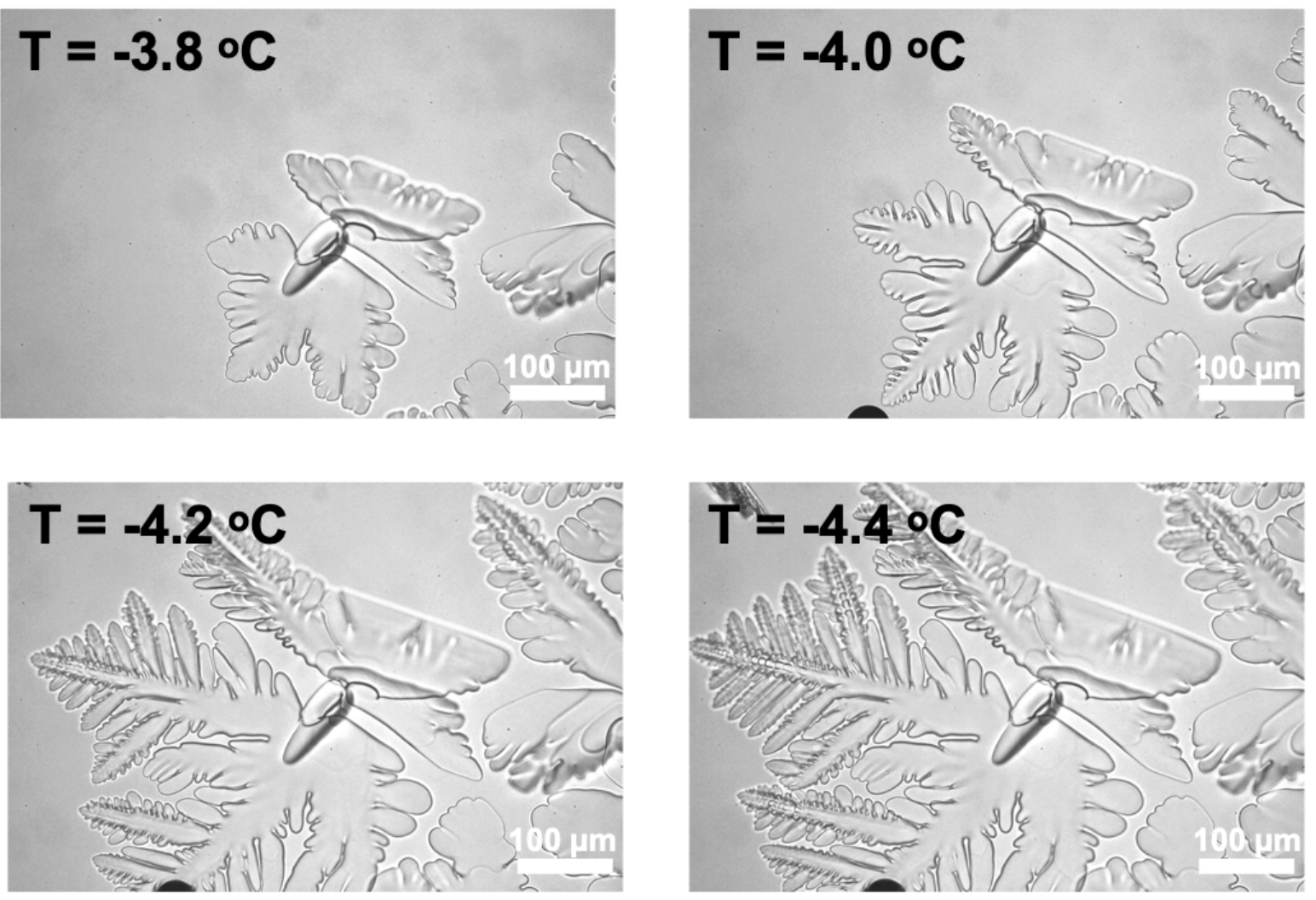

Figure S36. Modified sucrose "sandwich" ice shaping for $5 \mathrm{mg} \cdot \mathrm{mL}^{-1}$ of $\mathrm{PVP}_{40}-b$-PDAAm 200 diblock copolymer vesicles. 


\section{References}

(1) Tomczak, M. M.; Marshall, C. B.; Gilbert, J. A.; Davies, P. L. A Facile Method for Determining Ice Recrystallization Inhibition by Antifreeze Proteins. Biochem. Biophys. Res. Commun. 2003, 311 (4), 1041-1046.

(2) Smallwood, M.; Worrall, D.; Byass, L.; Elias, L.; Ashford, D.; Doucet, C. J.; Holt, C.; Telford, J.; Lillford, P.; Bowles, D. J. Isolation and Characterization of a Novel Antifreeze Protein from Carrot (Daucus Carota). Biochem. J. 1999, 340 ( Pt 2 (Pt 2), 385-391.

(3) Kumble, K. D.; Demmer, J.; Fish, S.; Hall, C.; Corrales, S.; DeAth, A.; Elton, C.; Prestidge, R.; Luxmanan, S.; Marshall, C. J.; Wharton, D. A. Characterization of a Family of Ice-Active Proteins from the Ryegrass, Lolium Perenne. Cryobiology 2008, 57 (3), 263-268.

(4) Kasper, J. C.; Friess, W. The Freezing Step in Lyophilization: Physico-Chemical Fundamentals, Freezing Methods and Consequences on Process Performance and Quality Attributes of Biopharmaceuticals. Eur. J. Pharm. Biopharm. 2011, 78 (2), 248263.

(5) Whale, T. F.; Murray, B. J.; O’Sullivan, D.; Wilson, T. W.; Umo, N. S.; Baustian, K. J.; Atkinson, J. D.; Workneh, D. A.; Morris, G. J. A Technique for Quantifying Heterogeneous Ice Nucleation in Microlitre Supercooled Water Droplets. Atmos. Meas. Tech. 2015, 8 (6), 2437-2447.

(6) DeMott, P. J.; Möhler, O.; Cziczo, D. J.; Hiranuma, N.; Petters, M. D.; Petters, S. S.; Belosi, F.; Bingemer, H. G.; Brooks, S. D.; Budke, C.; Burkert-Kohn, M.; Collier, K. N.; Danielczok, A.; Eppers, O.; Felgitsch, L.; Garimella, S.; Grothe, H.; Herenz, P.; Hill, T. C. J.; Höhler, K.; Kanji, Z. A.; Kiselev, A.; Koop, T.; Kristensen, T. B.; Krüger, K.; Kulkarni, G.; Levin, E. J. T.; Murray, B. J.; Nicosia, A.; O’Sullivan, D.; Peckhaus, A.; Polen, M. J.; Price, H. C.; Reicher, N.; Rothenberg, D. A.; Rudich, Y.; Santachiara, G.; Schiebel, T.; Schrod, J.; Seifried, T. M.; Stratmann, F.; Sullivan, R. C.; Suski, K. J.; Szakáll, M.; Taylor, H. P.; Ullrich, R.; Vergara-Temprado, J.; Wagner, R.; Whale, T. F.; Weber, D.; Welti, A.; Wilson, T. W.; Wolf, M. J.; Zenker, J. The Fifth International Workshop on Ice Nucleation Phase 2 (FIN-02): Laboratory Intercomparison of Ice Nucleation Measurements. Atmos. Meas. Tech. 2018, 11 (11), 6231-6257.

(7) Polen, M.; Brubaker, T.; Somers, J.; Sullivan, R. C. Cleaning up Our Water: Reducing Interferences from Nonhomogeneous Freezing of "pure" Water in Droplet Freezing Assays of Ice-Nucleating Particles. Atmos. Meas. Tech. 2018, 11 (9), 5315-5334.

(8) Bell, C. A.; Hedir, G. G.; O'Reilly, R. K.; Dove, A. P. Controlling the Synthesis of Degradable Vinyl Polymers by Xanthate-Mediated Polymerization. Polym. Chem. 2015, 6 (42), 7447-7454.

(9) Ferguson, C. J.; Hughes, R. J.; Nguyen, D.; Pham, B. T. T.; Gilbert, R. G.; Serelis, A. K.; Such, C. H.; Hawkett, B. S. Ab Initio Emulsion Polymerization by RAFT-Controlled Self-Assembly. Macromolecules 2005, 38 (6), 2191-2204. 